

\section{DISCLAIMER}

This information was prepared as an account of work sponsored by an agency of the U.S. Government. Neither the U.S. Government nor any agency thereof, nor any of their employees, makes any warranty, expressed or implied, or assumes any legal liability or responsibility for the accuracy, completeness, or usefulness, of any information, apparatus, product, or process disclosed, or represents that its use would not infringe privately owned rights. References herein to any specific commercial product, process, or service by trade name, trade mark, manufacturer, or otherwise, does not necessarily constitute or imply its endorsement, recommendation, or favoring by the U.S. Government or any agency thereof. The views and opinions of authors expressed herein do not necessarily state or reflect those of the U.S. Government or any agency thereof. 


\title{
Computer-Based Procedures for Field Workers in Nuclear Power Plants: Development of a Model of Procedure Usage and Identification of Requirements
}

\author{
Johanna Oxstrand and Katya Le Blanc
}

April 2012

Idaho National Laboratory

Idaho Falls, Idaho 83415

http://www.inl.gov

Prepared for the

U.S. Department of Energy

Office of Nuclear Energy

Under DOE Idaho Operations Office

Contract DE-AC07-05ID14517 



\title{
Computer-Based Procedures for Field Workers in Nuclear Power Plants: Development of a Model of Procedure Usage and Identification of Requirements
}

\author{
INL/EXT-12-25671
}

April 2012

Approved by:

Name

Title [optional]

Name

Title [optional]

Name

Title [optional]

Name

Title [optional]
Date

Date

Date 



\section{EXECUTIVE SUMMARY}

This research effort is a part of the Light Water Reactor Sustainability (LWRS) Program, which is a research and development (R\&D) program sponsored by the Department of Energy, performed in close collaboration with industry research and developments programs, to provide the technical foundations for licensing and managing the long-term, safe and economical operation of current nuclear power plants. Most currently operating nuclear power plants will soon begin reaching the end of their 60-year operating licenses granted by the United States (US) Nuclear Regulatory Commission. If these plants do not operate beyond 60 years, the total fraction of generated electrical energy from nuclear power will begin to decline - even with the modest addition of new nuclear generating capacity. The LWRS Program serves to help the US nuclear industry adopt new technologies and engineering solutions that facilitate the continued safe operation of the plants and extension of the current operating licenses.

With advances in nuclear power plant (NPP) design, the current fleet of nuclear plants will be soon competing with new reactors both in terms of efficiency and attracting the available workforce. While the current fleet is installing technological upgrades to their systems, the fact remains that they will remain less technologically advanced as the newly built plants. However, by introducing new technical solutions in the current fleet the gap between the old and new plants can be reduced. The effort to bridge this gap between the current fleet and new plants is an important step in the mitigation of workforce loss to new plants. One step in this process is to phase out the paper-based procedures (PBPs) that are currently used at most nuclear power plants and to replace them with computer-based procedures (CBPs). Before such an extensive replacement effort is conducted, there are many underlying research issues that need to be investigated and resolved, especially in the fields of human factors and humanmachine interaction. Most of the existing research focuses on CBPs for new and highly integrated systems. This research can be difficult to adapt to the current fleet since there are different challenges involved when CBPs are to be incorporated into existing systems. The goal for this research effort is to define requirements for CBPs that will ensure that the CBPs will be an improvement compared to current PBPs. The research effort does not focus on how to display PBPs on an electronic device. Instead, the focus is to evaluate how to streamline and distill the information in the paper-based procedure in order to increase efficiency, improve the ease of use, and reduce opportunities for errors.

Most existing research in the area of CBPs primarily focuses on CBP systems for operations in the main control room. There has been very little research conducted that focus on CBPs for field workers and how research can help these field organizations to increase their efficiency and improve human performance. Therefore, this specific research effort has a strong focus on field workers. In a long term perspective all organizations that conduct proceduredriven tasks that affect the plant will be covered, including main control room operations.

During the course of the research effort's first year a series of activities will be conducted. These include a literature review, a qualitative study; a user needs 
survey, and an evaluation study. The main objectives for the first year of the present research effort are to:

1. Determine the challenges utilities are having with current PBP systems,

2. Identify requirements for CBPs for field procedures,

3. Develop a prototype CBPs system based on the requirements identified,

4. Evaluate the CBP prototype, and

5. Define an industry-wide vision and path forward for CBP deployment.

The researchers reviewed existing CBP research and guidelines and procedure use and writer's guides. Based on the insights from the literature review, the team concluded that the existing research does not sufficiently address areas such as design guidelines for CBPs. Nor does the literature sufficiently address CBPs for field workers. There is a gap between the existing literature and what is needed to address the nuclear industry's needs. The current research effort aims to minimize this gap.

The qualitative study consisted of three information gathering efforts: Observations, Interviews, and Focus Groups. The primary goal of the qualitative study was to develop a model of procedure use; secondary goals were to validate and refine the problem statement, develop an information flow diagram, determine the feasibility of some of the potential CBP solutions, and to identify requirements for CBPs. The observations focused on two main types of information: 1) Activities involved in the execution of a task and 2) Information related to communication and information flow while a task is executed. The researchers conducted fifteen semi-structured interviews with field operators and maintenance technicians. The questions asked in the interviews aimed to address procedure use as well as procedure adherence. The goal was to gain a deeper understanding of what would cause the operator to deviate from the procedure, what would cause the operator to stop work and contact the supervisor, and what physical and cognitive functions are involved in the execution of a procedure step. The purpose of the focus groups was to discuss how technology can support field workers as well as what functions are needed in order to make a computerbased procedure system useful for the field worker. Insights from the focus qualitative study included the need for a set of requirements and standards for CBPs, and the need to design CBPs in a manner that will to enhance human performance compared to PBPs. A CBP system that simply mimics PBPs and displays them on an electronic device would not be enough of an improvement to justify a migration to CBPs. Another important insight gained is utilities are reluctant to be the first one to implement CBPs. The risk that regulators will not accept a CBP system makes the cost associated with developing and implementing CBPs difficult to justify However, utilities' would be mitigated or at least more manageable if the industry as a whole moved forward with CBPs.

One of the purposes of the observations, interviews, and focus groups was to map the task flow and the information flow related to procedure use in the plant. The task flow aimed to identify work processes and mental processes involved in carry out procedure-driven tasks in the field. The goal of the information flow mapping exercise was to identify how information is transferred during the execution of a procedure-driven task. 
The research team conducted a user needs analysis to gain a better understanding of the nuclear utilities' current plans for implementing CBPs, the current infrastructure in place to support CBPs, as well as the perceived or real barriers to implement CBPs systems. The focus groups discussions were the initial part of this analysis. To follow up on the information gathered in these discussions, a utility survey was conducted. One hundred percent of the participating utilities reported that CBPs for field operators were part of their long-term vision and sixty-six percent reported that CBPs for control room operators were in the long-term vision, indicating that utilities are indeed interested in moving forward with implementing CBPs

The research team could not identify an existing model of procedure usage in any of the research reviewed in during the literature review effort. This was identified as one potential explanation to why the nuclear industry has found it difficult to apply the research to the real environment in the plant. Therefore, a model of procedure usage was developed based in the insights from the studies conducted. The purpose of the model is to identify the physical and cognitive actions involved in the execution of one procedure step as well as potential error traps and what factors affect the risk of these human errors. The model of procedure usage contains the following elements:

1. Detailed task flow

2. Description of the techniques used to make decisions

3. Description of the conditions that must be satisfied to ensure task success

4. Description of the cognitive factors that influence the error likelihood

The model of procedure usage is used by the research team both in the process of identifying requirements for CBPs and in the prototype development process. It is important that the error traps identified in the model are adequately addressed and that the cognitive load on the operator is reduced.

The research team developed a general set of requirements for CBPs for field operators; the identification, definition, and selection process was based on an analysis of the model of procedure usage and a review of basic psychological and human factors literature. The research team complemented the set of general requirements with a list of specific CBP requirements for field operators. This list of requirements was developed based on review of existing CBP guidance. The general requirements state that CBPs should:

1. Guide operators through the logical sequence of the procedure. The CBPs should be designed so that they automatically take the operators through the specified procedure path based on initial conditions and operator input.

2. Ease the burden of place-keeping for the operator. CBPs should keep track of where the operator is in the procedure, should mark steps as completed, and should highlight the current step.

3. Make the action steps distinguishable from information gathering steps. CBPs should use some method to differentiate steps for which an operator must actually manipulate the plant versus when he must simply check a condition or value.

4. Alert operator to dependencies between steps. Typically, the operator has to rely on previous experience or on a caution or warning in order to identify 
the situations in which he needs to read ahead in the steps. CBPs should alert the operator when he reaches a step with dependencies, rather than relying on him to read ahead (or remember from previous experience) to detect the dependency. Additionally, if a CBP system has access to real-time plant data the system should alert the operator when plant status changes in a manner that affects the operator's task.

5. Ease the burden of correct component verification for the operator. CBPs should employ some method to automate correct component verification (e.g., include barcode scanning or text recognition functionality).

6. Ease the identification and support assessment of the expected initial conditions. Some method of illustrating the expected initial conditions in a simple and easy to understand manner should be available to the operator through the CBPs. For example a schematic or piping and instrument diagram of the relevant equipment could be available on-demand.

7. Ease the identification and support assessment of the expected plant and equipment response. Some method of illustrating the expected equipment and plant response in a simple and easy to understand manner should be available to the operator through the CBPs. For example a schematic or Piping and Instrument diagram of the relevant equipment could be available on-demand.

8. Include functionality that improves communication. In the event that an operator encounters a situation that he needs to contact a supervisor to resolve, he needs to be able to efficiently and accurately describe the problem. Tools such as texting, capturing photographs and streaming video have all been identified as highly desirable to have built into any device that display CBPs.

Examples of items on the list of requirements specific for field CBPs are that they should:

1. Be designed so that the operator controls the procedure pace.

2. Make calculations when the necessary information is available.

3. Alert users when procedure steps or conditions have been violated.

4. Alert users when conditions require transitioning to another procedure.

5. Evaluate step logic when the necessary information is available.

6. Be designed so that it is easy for the user to "undo" an unintended or incorrect action (an error of commission).

7. Allow the operator to look ahead and back in the procedure.

In the next phase of this research effort (starting April $1^{\text {st }}, 2012$ ), the research team will develop prototypes of CBP user interfaces based on the results from the literature review and the qualitative study, which includes the model of procedure use and the identified requirements for CBPs. The results from the previous studies will help inform the selection of design concepts to implement and what specific issues related to procedure use and adherence to address. The prototypes will also be designed to test different functionalities that are of interest to investigate and evaluate. In the fall of 2012 an evaluation study will be conducted at a nuclear power utility. The study will focus on the use of the CBP 
and the current PBP version of the selected plant procedure, and the comparison of the two. Field workers at the plant will be observed using both versions of the procedure. The purpose of the evaluation study is to compare the use and execution of the CBP to the current use and execution of the PBP version. The CBP's user interface design will also be evaluated in terms of usability, acceptability, and potential increased process efficiency.

This report describes the literature review, qualitative study, and the utility study in detail; and contains a brief summary of the planned evaluation study. The data and gathered and insights gained from first three activities were used to develop a model of procedure usage and requirements for CBPs. The model of procedure usage proved to be an essential tool to understand the actual physical and cognitive activities involved when executing a procedure step. The requirements were developed to address the specific challenges identified in the qualitative study and in the model. 


\section{ACKNOWLEDMENTS}

The authors would like to express special gratitude to the following people for their collaboration and support of this research effort. William Russell, South Texas Project, for his support in understanding the problem space and introduction to procedure reliability. Thomas Waicosky, Catawba Nuclear Station, for the countless hours spent discussing the problem space with us as well as organizing the qualitative study. Without Thomas' support the study would not have been as successful as it was. Gregory Robison, Duke Energy, for supporting the qualitative study. Bruce Gordon and Carlos Williams, Palo Verde, for their support in the process of identifying requirements as well as the prototype development.

The research team also wants to extend its gratitude to all the other utilities and research institutes that participated in the qualitative study and the utility survey. 


\section{CONTENTS}

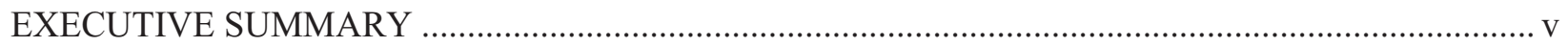

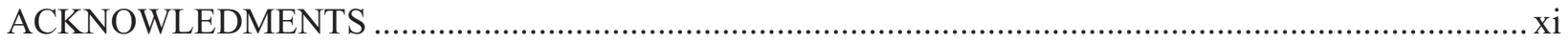

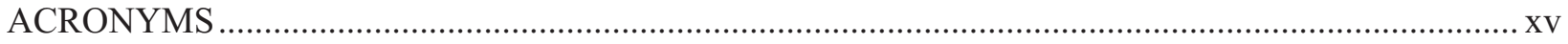

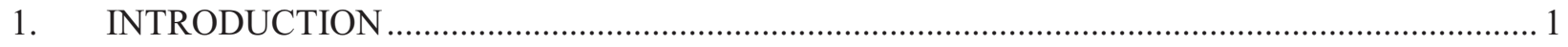

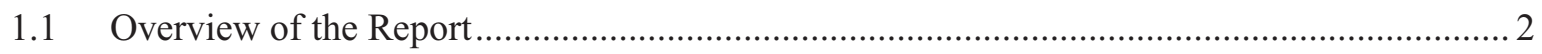

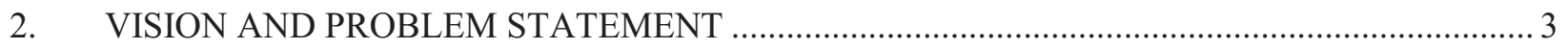

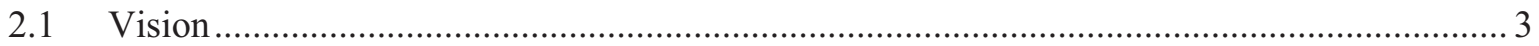

2.2 Problem Statement and Hypothesis ......................................................................... 4

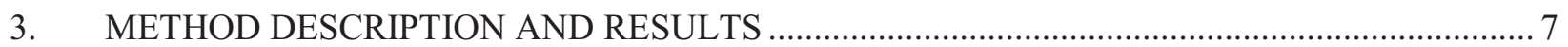

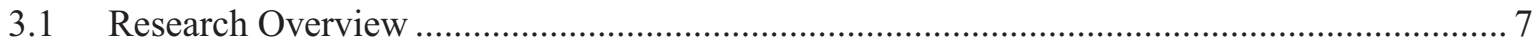

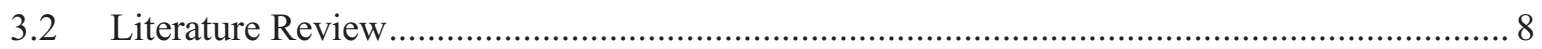

3.2.1 Evaluation of Computer-Based Procedures .......................................................... 8

3.2.2 Nuclear Industry Documents Focusing on Procedure Use and Adherence................ 11

3.2.3 Design, Development, and Review Guidelines for CBPS .................................... 12

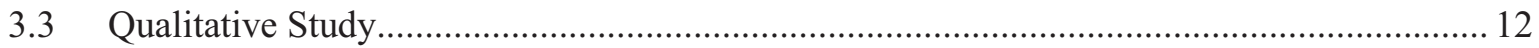

3.3.1 Field Worker Observations, Interviews and Focus Groups .................................... 13

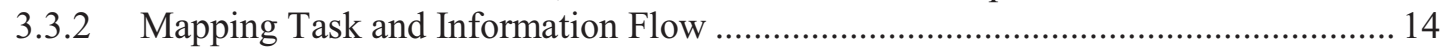

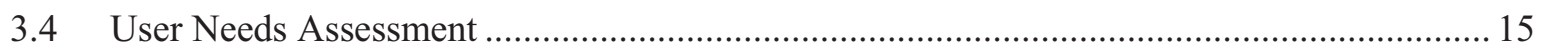

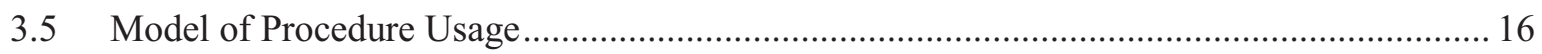

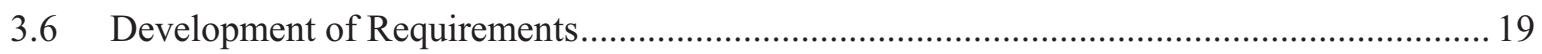

3.7 Prototype Development, Testing, and Evaluation........................................................ 20

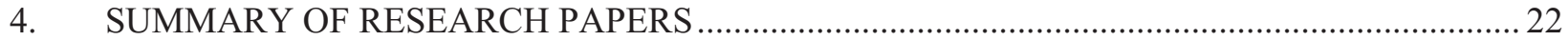

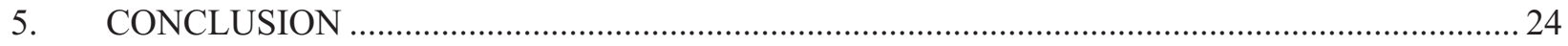

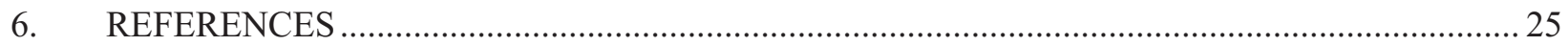

Appendix A Model of Procedure Usage - Results from a Qualitative Study to Inform Design of

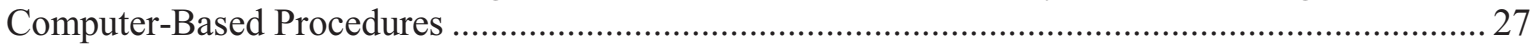

Appendix B A Model of Operator Interaction with Field Procedures: Insights for Computer-

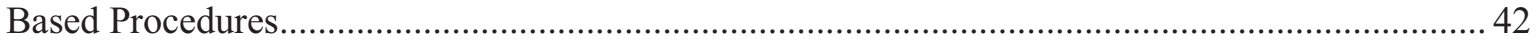

Appendix C Requirements for Computer Based-Procedures for Nuclear Power Plant Field

Operators - Results from a Qualitative Study .............................................................................. 49

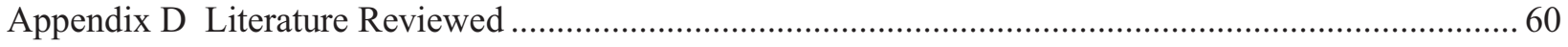

Appendix E The Protocol Used In The Qualitative Study .............................................................. 68

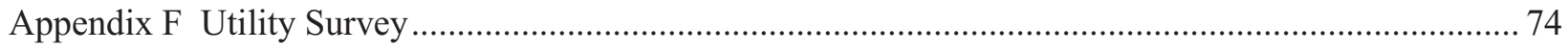




\section{FIGURES}

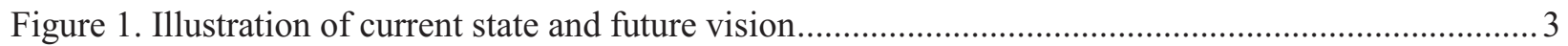

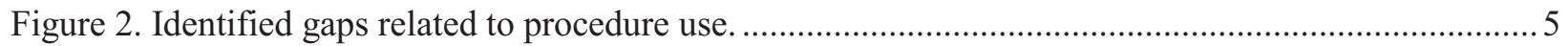

Figure 3. Research activities to be conducted the first year.................................................................... 8

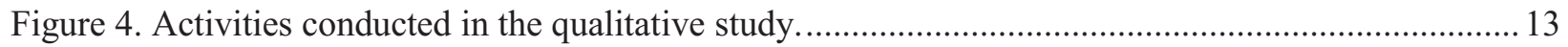

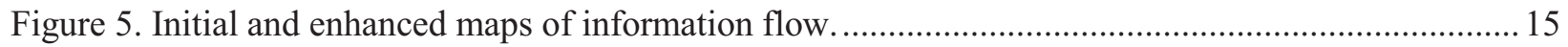

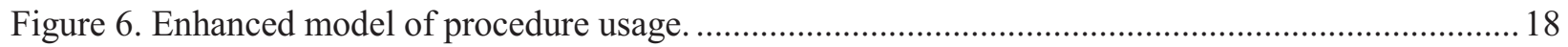

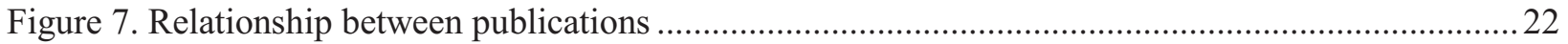

TABLES

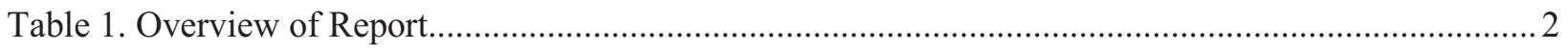

Table 2. Experimental evaluation of computer-based procedures in the nuclear industry ......................... 9

Table 3. Summary of reviewed procedure writing and adherence documents. ....................................... 11

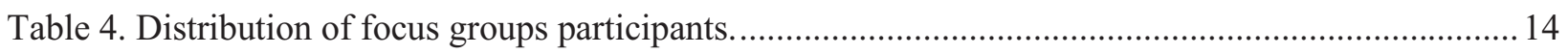

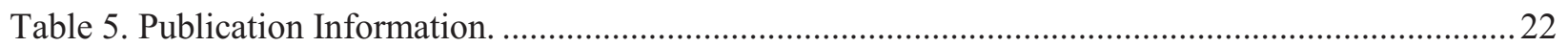




\section{ACRONYMS}

$\begin{array}{ll}\text { CBP } & \text { Computer-Based Procedures } \\ \text { DOE } & \text { Department of Energy } \\ \text { EPRI } & \text { Electrical Power Research Institute } \\ \text { IAEA } & \text { International Atomic Energy Agency } \\ \text { IEEE } & \text { Institute of Electrical and Electronics Engineers } \\ \text { INL } & \text { Idaho National Laboratory } \\ \text { INPO } & \text { Institute of Nuclear Power Operations } \\ \text { LWRS } & \text { Light-Water Reactor Sustainability } \\ \text { NPP } & \text { Nuclear Power Plant } \\ \text { NRC } & \text { Nuclear Regulatory Commission } \\ \text { PBP } & \text { Paper-Based Procedures } \\ \text { PPA } & \text { Procedure Professionals Association } \\ \text { R\&D } & \text { Research and Development }\end{array}$




\section{INTRODUCTION}

Most currently operating nuclear power plants will soon begin reaching the end of their 60 -year operating licenses granted by the United States (U.S.) Nuclear Regulatory Commission. If these plants do not operate beyond 60 years, the total fraction of generated electrical energy from nuclear power will begin to decline - even with the modest addition of new nuclear generating capacity. This research effort is a part of the Light-Water Reactor Sustainability (LWRS) Program, which is a research and development (R\&D) program sponsored by Department of Energy (DOE), performed in close collaboration with industry $R \& D$ programs, to provide the technical foundations for licensing and managing the long-term, safe, and economical operation of current nuclear power plants. The LWRS program serves to help the U.S. nuclear industry adopt new technologies and engineering solutions that facilitate the continued safe operation of the plants and extension of the current operating licenses.

With advances in nuclear power plant (NPP) design, the current fleet of nuclear plants will be soon competing with new reactors both in terms of efficiency and in attracting the future workforce. While the current fleet is installing technological upgrades to their systems, the fact remains that they will remain less technologically advanced than newly built plants. However, by introducing new technical solutions into the current fleet, the gap between existing and advanced plants can be reduced. The effort to bridge this gap between the current fleet and new plants is an important step in the mitigation of workforce loss to new plants. One step in this process is to phase out the paper-based procedures (PBPs) that are currently used at most NPPs and replace them with computer-based procedures (CBPs).

Even though PBPs have successfully ensured safe plant operation for decades, they have also been identified as a potential contributor to human error. One of the main issues with PBPs is that they are static while the environment on which they should apply is dynamic (i.e. constantly changing). Due to the static nature of PBPs and the dynamic systems, most of the PBPs are written to accommodate many different scenarios. Hence, the procedure layout forces the operator to search through a large amount of irrelevant information to locate the pieces of information relevant for the task and situation at hand, which has potential consequences of taking up valuable time when operators must be responding to the situation, and potentially leading operators down an incorrect response path. Other recognized challenges related to PBPs are the management of multiple procedures, place-keeping, and finding the correct procedure for the task at hand (Fink et al. 2009). The static nature of the PBPs also forces the operator to rely on other sources of additional information to ensure a functional and accurate understanding of the current plant status. These sources can be things such as drawings, manuals, operational experience, and the operator's own knowledge and expertise. The operator typically has to carry additional papers and/or maintain a lot of information active in his or her memory to have the additional information available when needed.

Much of the existing research in the area of CBPs focuses on procedures for new designs and highly integrated systems. This research can be difficult to adapt to the current NPP fleet because there are different challenges involved when CBPs are to be incorporated into existing systems. In the new system designs, the CBPs are designed as an integral part of the highly coupled system from the beginning of the design process. However, this is not feasible in an existing plant, as it would require a redesign of most systems. The challenge for the existing NPP fleet is to find ways to incorporate the use of CBPs with the existing systems. Therefore, the requirements of CBPs use, design, and implementation will be different for the current fleet than for new-builds. Despite a 30-year history of research on CBPs for main control rooms, almost no NPPs are currently using them, in part because of the difficulty in adapting them to existing plants.

Additionally, existing research in the area of CBPs has primarily focused on CBP systems for operations in the main control room, and more specifically on emergency operating procedures. There has been very little research conducted that focuses on CBPs for field workers and how research can help these field organizations to increase their efficiency and improve human performance. The term field workers is used to describe field operations, chemistry operations, maintenance, and any other 
organization that might exist in the NPP that conducts procedure-driven tasks out in the plant. Utilities have expressed a need for research tailored to the specific needs of field workers, because the limitations of PBPs are particularly relevant for field work.

The design of field procedures is different than those in the main control room. Procedures in the control room are mostly designed to handle events or changes (e.g., transitions or mode changes) executed by the use of a control device such as a handle, button, or mouse. The procedures used in the field are mostly designed for execution of specific tasks (e.g., to isolate a system or start a pump) where the field worker manually operates the physical component. The environment in the control room is also quite different compared to the field. The control room is a smaller space with stable environmental conditions. However, the plant is a much larger environment, and the conditions in the plant vary depending on location and plant status. Throughout the work day the field worker may execute tasks in locations with varying temperatures and radiological levels. The field worker also travels much more during the day than the control room operator. For example, the field worker may climb ladders or crawl in tight spaces to get to a component, and while doing such the field worker also needs to physically carry all of the materials they need to perform the task at hand. This could be a paper print-out of the procedure, manuals, blueprints, and other information needed. As a result, utilities see limitations in adapting the current CBP research to field worker organizations. However, a dedicated research effort on CBPs for field workers may demonstrate the value of CBPs and gain the momentum for their use. In the long-term, a successful demonstration of the value of CBPs in the field might help the implementation of CBPs in the main control room as well.

The goal of the present research effort is to define requirements for CBPs used in the field that will ensure that the CBPs are an improvement over current PBPs. The focus of the research is on CBPs for field workers, but the research may be extended to cover CBPs for the main control room in the future. The research team's long-term vision is to cover all organizations that conduct procedure-driven tasks that affect the plant. This research effort does not simply focus on how to display existing PBPs on an electronic device. Instead, the research team is investigating how to streamline and distill the information in the PBP to increase efficiency, improve the ease of use, and reduce opportunities for errors.

\subsection{Overview of the Report}

The report contains three distinctly separate parts: the main body of the research report, appended publications based on this research, and additional information related to the research. Table 1 provides an overview of the three parts as well as a guide to where to find them within the report. The publications on which the summary is based consist of three research papers that the research team has submitted to conferences and are currently in press.

Table 1. Overview of Report.

\begin{tabular}{|l|l|l|l|}
\hline & \multicolumn{1}{|c|}{ Part of Report } & \multicolumn{1}{c|}{ Description } & \multicolumn{1}{c|}{ Pages } \\
\hline 1 & Summary & A summary of the research performed. & $1-26$ \\
\hline 2 & $\begin{array}{l}\text { Publications } \\
\text { (the three first appendixes) }\end{array}$ & $\begin{array}{l}\text { Research papers based on the performed research. } \\
\text { Provide detailed descriptions of conducted studies and } \\
\text { results. }\end{array}$ & $27-64$ \\
\hline 3 & Other Appendixes & Additional information related to the conducted research. & $65-79$ \\
\hline
\end{tabular}




\section{VISION AND PROBLEM STATEMENT}

To ensure a clear research focus, the research team defined a vision, a problem statement, and a hypothesis. The focus of this research is to enhance field workers' procedural performance with CBPs. Therefore, it is important to ensure that the commercial nuclear industry's needs related to procedures are accurately addressed. To do such, the research team involved utility partners in the identification and development process of the vision, problem statement, and hypothesis. These three statements will be used as a qualitative measure to make sure the research progresses in a successful manner. This section describes the process of formulating the statements as well as the final definitions of the vision, problem statement, and hypothesis.

\subsection{Vision}

The vision statement can be summarized as follows: operator performance - and ultimately plant performance - may be improved by significant advancements in how procedure usage is achieved with new technologies. Plans to upgrade existing plants with digital equipment and wireless technology present an opportunity to enhance procedures by transforming the existing PBPs to CBPs. These CBPs have the potential to integrate plant information (including plant mode, equipment status, and procedure relevant plant parameters) and make it readily available to plant personnel in real time. CBPs with this enhanced functionality will be dynamic and context-sensitive, affording the opportunity to mitigate many of the issues associated with static PBPs.

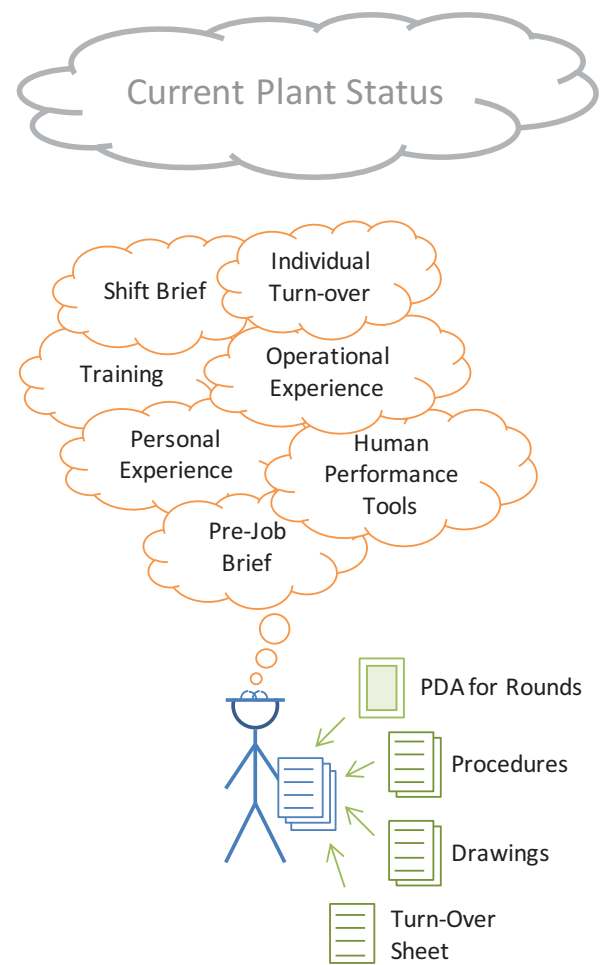

Current

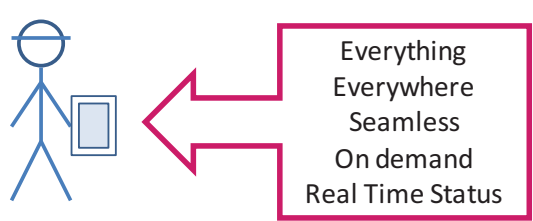

Future

Figure 1. Illustration of current state and future vision 
Currently, the field operator typically has to carry procedures, drawings, turnover sheet (information shared and captured during the shift turnover), and a handheld device (used to capture values checked throughout the round) out to the field. Along with these things (which the field operator must physically carry), he also needs to keep things such as operational experience, human performance tools, information shared during shift turnover, etc., in his memory. The field operator also needs to maintain an accurate and updated awareness and understanding of the current plant status and other ongoing work activities. When executing the task, the operator has to incorporate the physical tools with the information stored in his memory, which may pose a great load on his working memory capacity.

The research team envisions that in the not-so-far future, the field operator will be using one device that seamlessly integrates plant information (plant mode, equipment status, etc.), other work in progress, operational experience, just-in-time training, and CBPs. The procedures will be dynamic and contextsensitive in the sense that they will automatically update the information and steps displayed to the operator based on current plant status and other work in progress. Figure 1 depicts the current state and the future vision.

\subsection{Problem Statement and Hypothesis}

The research team formulated an initial problem statement and hypothesis based on information gained from interviews with personnel at two different NPPs as well as on results from the conducted literature review. The literature review is described in Section 3.2, "Literature Review." The research team involved the utility collaboration partners in the formulation of the problem statement and hypothesis. The initial versions of the problem statement and hypothesis were later revised based on the deeper understanding of the problem, which was mainly gained as a result of the qualitative study. The description of the qualitative study is presented in Section 3.3, "Qualitative Study."

The process of formulating the problem statement began with the researchers identifying the general purpose of written procedures and identifying potential gaps in the ability of procedures to serve their main function. Written procedures are intended to guide operators through the complex tasks they must perform; however, there are two main gaps in the ability of written procedures to address all of the situations an operator may encounter. Those gaps are illustrated in Figure 2. The first gap (Gap A) between the real world and what the intended use of procedures (i.e., what they are intended to cover). Gap A exists due to the facts that procedures can only be written for events that humans can anticipate. This gap may be reduced by increased procedure quality and the manner procedures are written. However, even with the highest quality procedure, this gap is unlikely to ever be fully eliminated. Thus, the computer-based procedure research effort will not attempt to address this. The second gap (Gap B) is between procedure's intended use and the actual use of the procedures. The gap between procedures intended use and actual use (Gap B) is usually nonexistent. However, occasionally the operator may intentionally deviate from a procedure (i.e., a workaround) or make an unintentional error. This gap can be reduced by a greater focus of human factors and human system interaction in the design of procedures and procedure use. The computer-based procedure research effort will focus on Gap B. 


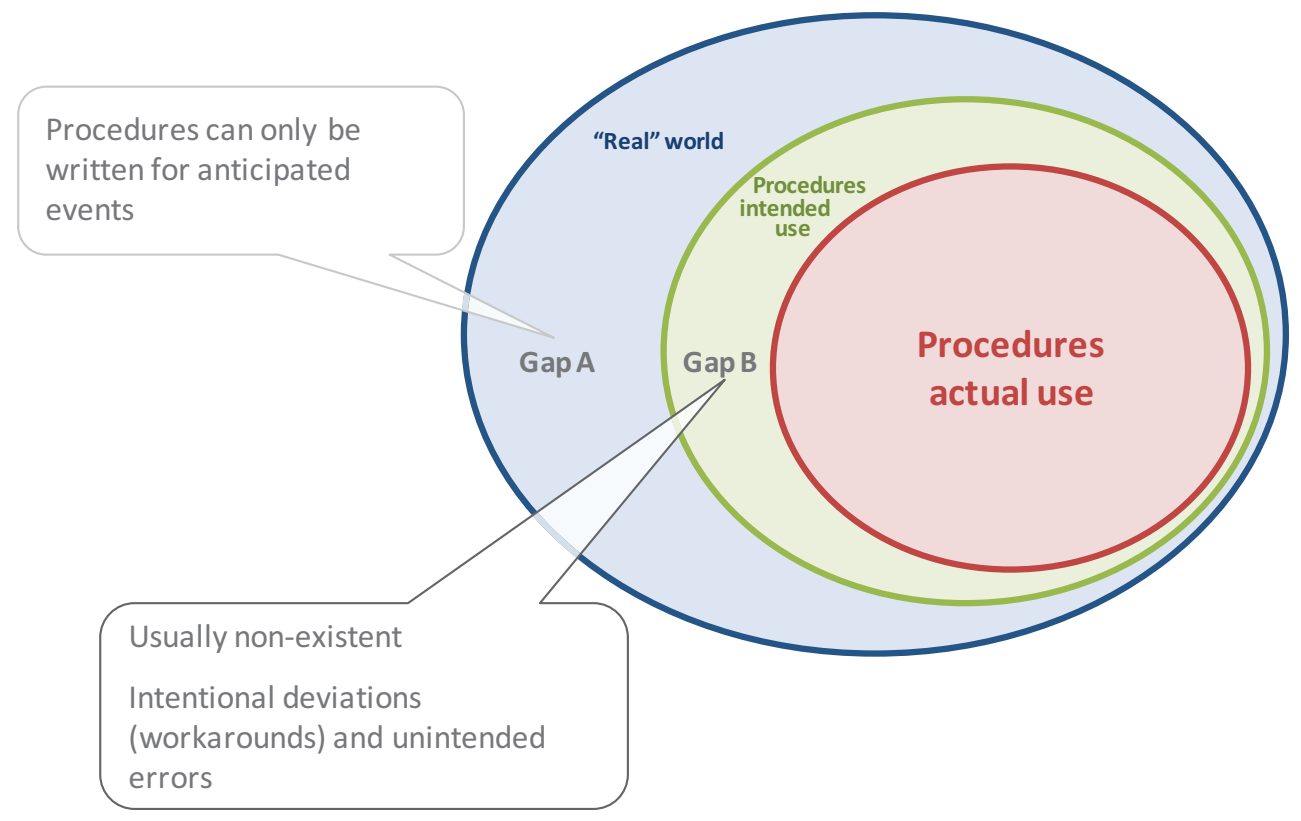

Figure 2. Identified gaps related to procedure use.

Initially, there was an emphasis on lack of procedure adherence due to the operators intentionally deciding to deviate from a procedure. In early conversations with collaboration partners, the research team captured statements such as "We must force the operator to follow the procedure at all times," and "Operators should not make decisions while being out in the field." The initial problem statement and hypothesis were formulated to address Gap B, and specifically non-adherence due to intentional deviations from procedures. These initial statements are described in the research paper, Model of Procedure Usage - Results from a Qualitative Study to Inform Design of Computer-Based Procedures (Appendix A). However, the results from the qualitative study revealed that the lack of procedure adherence is not mainly due to intentional deviations. It was found that operators will stop work as soon as they encounter something that makes them question the situation instead of making the decision to deviate from the procedure. The operator will call a supervisor or other coworker qualified to decide how to resolve the situation. Hence, lack of procedure adherence is unlikely due to intentional deviations in most cases. Instead, procedure non-adherence and human errors related to procedure use are more likely to be caused by unintentional operator errors. Even though research on CBPs has been conducted already (as described in the literature review section) the question of what is really wrong with PBPs for field workers has not yet been investigated in great detail. There is not a well-documented theory of why unintentional errors occur when using PBPs or how to best reduce the risk of them. However, there are a lot of assumptions of the deficiencies of PBPs. These deficiencies include the ease of unintentionally skip a step, the static nature of the procedure, and the cumbersome task of keeping track of current plant status and other work in progress. To understand how to best and most efficiently address the risk of unintentional operator errors with CBPs it is necessary to gain an detailed understanding of how PBPs are currently used as well as the underlying causes of operator error when executing a procedure-driven task. These findings resulted in a shift of the research focus from addressing intentional deviations from procedures to the reduction of the risk of unintentional errors during the execution of a procedure driven task. The final definition of the problem statement is as follows:

Numerous events and subsequent corrective actions are attributed to procedural usage issues in NPPS. The PBPs currently utilized pose challenges in that they are static while actual plant conditions are dynamic. Therefore, the procedures may include sections or steps not applicable to the current situation as well as cautions or warnings that are misleading or confusing given the current plant status. These issues are all known to lead to unintended or erroneous actions. 
Based on the problem statement a research hypothesis was defined. The hypothesis will be tested multiple times throughout the span of the research effort. The identified hypothesis is:

The risk of unintentional operator errors or erroneous actions conducted by plant personnel can be greatly reduced with the development of procedures that are both dynamic and context sensitive. 


\section{METHOD DESCRIPTION AND RESULTS}

The general approach to this research includes a mix of qualitative and quantitative data collection activities. All the activities are designed so that their results inform the next activity. This section describes the activities that are to be conducted during the first year of the research effort. These activities are (1) Literature review, (2) Qualitative study, (3) Prototype development, and (4) Evaluation Study. These four activities will help inform the path forward for the second year of the research effort. A description of the methods used in the studies, the purposes and goals, and a summary of the results are presented below. The main focus will be on the literature review and the qualitative study; however, a brief description of the other tasks will be provided as well.

\subsection{Research Overview}

The main objectives for the first year of the present research effort are to:

1. Determine the challenges utilities are having with current PBP systems

2. Identify requirements for CBPs for field procedures

3. Develop a prototype CBPs system based on the requirements identified

4. Evaluate the CBP prototype

5. Define an industry-wide vision and path forward for CBP deployment.

To address these objectives the research effort was divided into four main parts. Figure 3 shows the four parts and how they relate to each other. The first part is a literature review of current and existing research related to CBPs and human factors. As a part of this review the researchers also benchmarked existing and proposed CBP systems. The literature review informs the qualitative study by identifying the gaps in the existing literature on CBPs. The qualitative study (represented as the second part in Figure 3) aims to develop a model of procedure use. This study included a data gathering effort at a NPP. The results from the study including the model of procedure use were used to define requirements for CBPs. Those requirements will be used to inform the third part - the development of CBP prototypes. Based on the model of procedure use and the identified requirements, prototypes will be developed to demonstrate different design concepts. The research team will conduct usability tests and gather feedback from field workers throughout the iterative development phase to ensure the validity and acceptance of the concepts. 


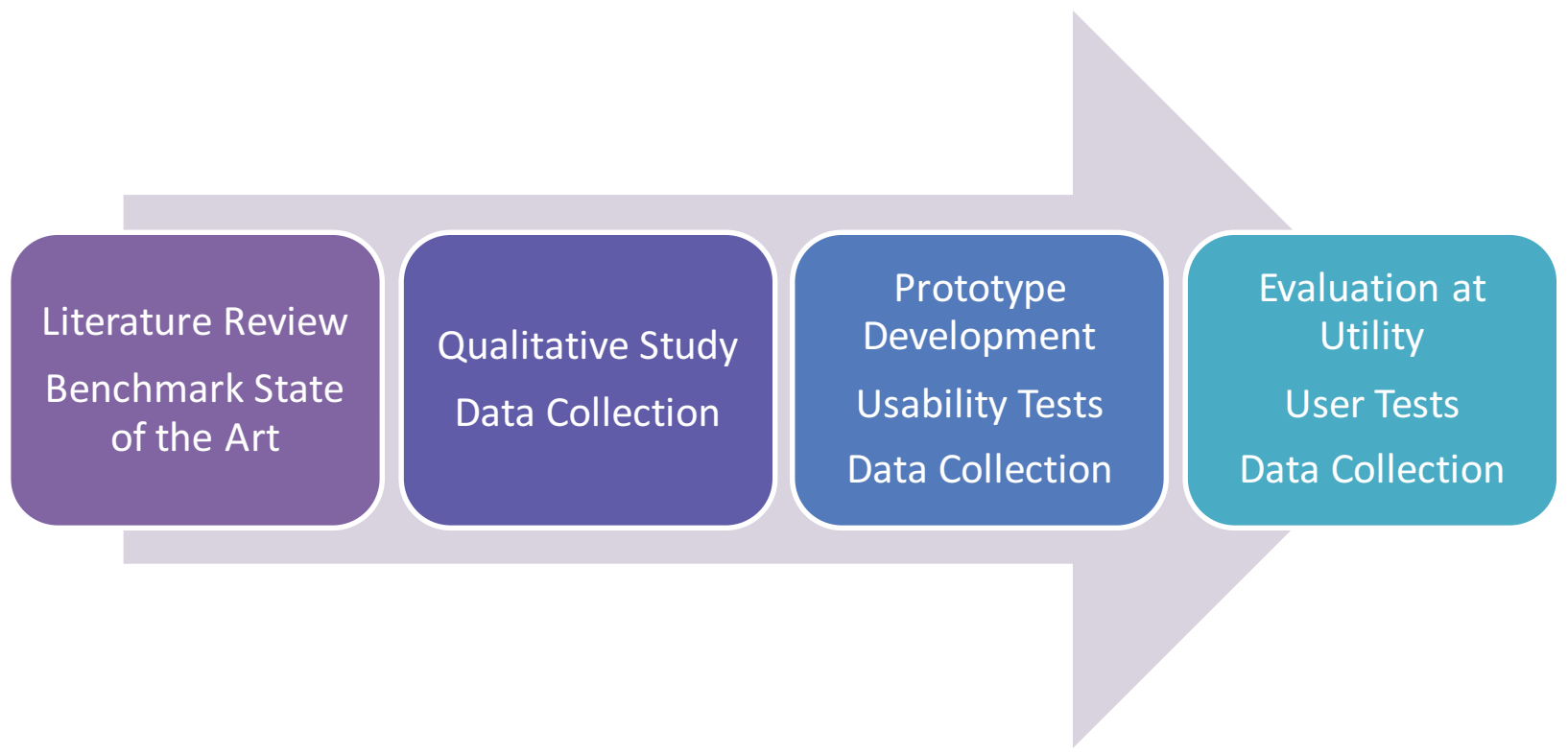

Figure 3. Research activities to be conducted the first year

When the prototypes are developed an Evaluation study will be conducted at a utility, which is the fourth part in Figure 3. The study will be designed to include user tests and data collection. All the activities conducted during first year of the research effort will inform the decision of the path forward for the next year. This decision will be made based on all results from the first year and in tight collaboration with the utility partners. In the process of making the decision topics such as what field worker organization to focus on next, which specific issues or problems this specific organization struggles with, and which CBP concepts should be explored to address these issues should be considered.

\subsection{Literature Review}

The literature review focused on three main literature categories:

1. Evaluation of CBPs

2. Nuclear industry documents focusing on procedure use and adherence

3. Design, development, and review guidelines for CBPs

The review of these three areas was aimed to inform the qualitative study, the development of a model of procedure use, and the identification of requirements for CBPs. A summary of the review is presented below. The summary in this section does not represent all the literature reviewed, but instead provides a brief discussion of the findings and results of existing CBP research, as well as a brief description of issues related to procedure use and adherence. For the complete list of literature reviewed, please see Appendix D.

\subsubsection{Evaluation of Computer-Based Procedures}

In order to better understand the specific impacts that CBPs might have on performance, the researchers reviewed literature that described empirical evaluations of existing CBP systems and prototypes. Table 2 below presents a summary of experimental evaluations of CBPs in the nuclear industry. The table includes the specific aspects or factors related to CBPs that investigators studied as well as their methodologies and their important findings. 
Table 2. Experimental evaluation of computer-based procedures in the nuclear industry

\begin{tabular}{|c|c|c|c|}
\hline Reference & $\begin{array}{l}\text { Aspects of CBPs } \\
\text { Investigated }\end{array}$ & $\begin{array}{c}\text { Evaluation } \\
\text { Methods/Measures }\end{array}$ & Key Findings \\
\hline $\begin{array}{l}\text { Xu, Song, Li, } \\
\text { Zhao, Luo, He, } \\
\text { \& Salvendy } \\
(2008)\end{array}$ & $\begin{array}{l}\text { - Crew } \\
\text { - Training/skill } \\
\text { level } \\
\text { - Presentation } \\
\text { style }\end{array}$ & $\begin{array}{l}\text { - Error rate } \\
\text { - Operation time }\end{array}$ & $\begin{array}{l}\text { - Presentation style had an effect on } \\
\text { error rate, but not operation time } \\
\text { - Skill level had an effect on both } \\
\text { error rate and operation time }\end{array}$ \\
\hline $\begin{array}{l}\text { Roth \& O’Hara } \\
(2002)\end{array}$ & $\begin{array}{l}\text { - Ability to use } \\
\text { CPBs } \\
\text { - Ability to switch } \\
\text { from PBPs to } \\
\text { CBPs } \\
\text { - Crew } \\
\text { communication }\end{array}$ & $\begin{array}{l}\text { - Expert observation } \\
\text { - Operator interviews }\end{array}$ & $\begin{array}{l}\text { - Crews were able to use CBPs } \\
\text { - Crews were able to switch CBPs to } \\
\text { PBPs without difficulty } \\
\text { - Communication was generally } \\
\text { good with CBPs, but a significant } \\
\text { communication breakdown was } \\
\text { identified }\end{array}$ \\
\hline $\begin{array}{l}\text { Huang \& } \\
\text { Hwang (2009) }\end{array}$ & $\begin{array}{l}\text { - CBPs versus } \\
\text { PBPs } \\
\text { - Team } \\
\text { performance }\end{array}$ & $\begin{array}{l}\text { - Error rates } \\
\text { - Operation time } \\
\text { - Workload } \\
\text { (subjective self report) } \\
\text { - Situation Awareness } \\
\text { (subjective self report) }\end{array}$ & $\begin{array}{l}\text { - CBPs enhanced performance as } \\
\text { measured by error rate and operation } \\
\text { time when compared with PBPs } \\
\text { - There was no significant difference } \\
\text { between PBPs versus CBPs on self- } \\
\text { report measures of Situation } \\
\text { Awareness and Workload } \\
\text { - There are no significant difference } \\
\text { between a team of } 1,2 \text {, or } 3 \\
\text { operators for errors, but } 1 \text { operator } \\
\text { took significantly longer than } 2 \text { or } 3\end{array}$ \\
\hline $\begin{array}{l}\text { Chung, } \\
\text { Daihwan \& Kim } \\
(2002)\end{array}$ & $\begin{array}{l}\text { - CBPs versus } \\
\text { PBPs in } \\
\text { conventional and } \\
\text { advanced main } \\
\text { control rooms }\end{array}$ & - Expert Observation & $\begin{array}{l}\text { - Crew communications are different } \\
\text { with CBPs than with PBPs }\end{array}$ \\
\hline $\begin{array}{l}\text { Jeffroy \& } \\
\text { Charron (1997) }\end{array}$ & $\begin{array}{l}\text { - CBPs versus } \\
\text { PBPs }\end{array}$ & $\begin{array}{l}\text { - Guided expert } \\
\text { observation of videos }\end{array}$ & $\begin{array}{l}\text { - This is a preliminary report, so no } \\
\text { findings are reported }\end{array}$ \\
\hline $\begin{array}{l}\text { Lee, Hwang \& } \\
\text { Wang (2005) }\end{array}$ & $\begin{array}{l}\text { - Embedded } \\
\text { versus separate } \\
\text { procedures }\end{array}$ & - Performance time & $\begin{array}{l}\text { - Embedded procedures led to faster } \\
\text { performance times than separate } \\
\text { procedures }\end{array}$ \\
\hline Converse (1995) & $\begin{array}{l}\text { - CBPs versus } \\
\text { PBPs }\end{array}$ & $\begin{array}{l}\text { - Time to initiate } \\
\text { procedure } \\
\text { - Time to complete } \\
\text { procedure } \\
\text { - Errors (deviation } \\
\text { from optimal sequence } \\
\text { of events) } \\
\text { - NASA TLX }\end{array}$ & $\begin{array}{l}\text { - Errors were lower with CBPs than } \\
\text { with PBPs } \\
\text { - Crews were slower with CBPs than } \\
\text { with PBPs }\end{array}$ \\
\hline
\end{tabular}


By reviewing the studies presented above in Table 2, the researchers hoped to gain a better understanding of the specific factors that make CBPs successful or unsuccessful. However, the research reviewed did not provide enough depth to fully illustrate what aspects of CBPs are desirable or undesirable. The results of most of the studies mentioned above were mostly aimed at determining whether operators could use the CBPs systems as well as the paper based system. The aim of this research project is to determine how to design a CBP system so that it is a significant improvement over PBPs in terms of human performance.

Although the existing research on CBPs is insufficient to draw broad conclusions as to what factors of CBPs are important to ensure successful implementation, some research has investigated specific factors that may be important to CBP design. For example, one study of suitable screen size for presenting procedures on a mobile device has been reviewed. Byrd and Caldwell $(2009,2011)$ conducted a research study where they compared procedure-based task performance using three mobile devices with different screen sizes (7in, 3.5in, and 2.8in). In the study a computer maintenance procedure was viewed and executed using a graphical user interface that simulated the different screen sizes. The results from 65 student participants indicated a significant difference in completion times between the different screen sizes. However, the subjective assessment in the study did not detect any significant in cognitive workload, errors of performance, or performance time between the uses of different screen sizes. The main conclusion drawn by Byrd and Caldwell is that when using the larger screen the user read more of the procedure before execution. When using a smaller screen the user sampled the procedure in longer intervals during execution. Thus, CPBs displayed on mobile devices may inevitably increase workload. Special care should be taken to ensure that the overall design of CBPs decreases workload when compared to PBPs.

Other studies, did not identify important aspects of CBPs, but did describe shortfalls of PBPs. In their study of CBPs and team size, Huang and Hwang (2009) identified the primary weaknesses of PBPs, which are currently used by most nuclear power plants. These aspects included:

1. Difficulty navigating within and between procedures

2. Missing steps, especially when returning to a partially completed procedure after an interruption

3. Experiencing difficulties in conceptually associating information with the corresponding control mechanism.

Jung et al. (2000) argue that the main reasons the operator's mental burden is high when using PBPs are place-keeping, concurrent execution of multiple procedures, continuously applicable steps, as well as the interpretation of procedures and intervention while continuing to monitor and control other systems. PBPs are static and therefore not integrated with plant information systems or control systems, which means that the operator has to rely on his memory or other cues for this information.

Park and Jung (2007) have developed a method for measuring the complexity of procedure driven tasks. They identified four main sources of complexity in procedural tasks including:

- The step information complexity (SIC) represents a complexity due to the amount of information to be processed by operators.

- The step logic complexity (SLC) denotes a complexity due to the logical sequence of the required actions to be accomplished by operators.

- The step size complexity (SSC) implies a complexity due to the amount of required actions to be accomplished by operators.

- The abstraction hierarchy complexity (AHC) indicates a complexity due to the amount of system knowledge that is indispensable for identifying the problem space of the required actions.

- The engineering decision complexity (EDC) connotes a complexity due to the amount of cognitive resources that are necessary to establish the proper decision criteria for the required actions. (p. 671) 
The measure that Park and Jung (2007) developed to quantify these sources of complexity is well correlated with measures of operator performance indicating that it is a valid measure of task complexity. Computer-based procedure systems should be designed to minimize these sources of complexity where they can.

\subsubsection{Nuclear Industry Documents Focusing on Procedure Use and Adherence}

An important step in identifying how operators actually use PBPs for building the model of procedure usage was identifying how operators are expected to use procedures. To understand the organizational expectations of procedure use and how to improve the process of procedure use, the research team reviewed the guidance documents most commonly used by the nuclear industry related to procedure use and adherence. The Institute for Nuclear Power Operations (INPO) defines procedure adherence as the understanding of a procedure's purpose, scope, and intent and following its direction (INPO, 2009). There are four procedure adherence principles that apply to every person who conducts procedure-driven tasks:

1. The user performs all actions as written in the sequence specified by the procedure. However, if the procedure cannot be used as written, then the activity is stopped and the issue is resolved before the user continues.

2. Procedures are followed as written, and users do not deviate from procedures except when specifically allowed by the procedure or by approved processes.

3. Procedures are reviewed prior to use to ensure that potential adherence problems are resolved.

4. Personnel are trained/qualified or are under the direct control of a trained/qualified individual when performing procedure steps.

The research team also reviewed six guidance documents for how to write procedures and how to ensure procedure adherence from three separate organizations. These organizations are Procedure Professionals Association (PPA), Institute for Nuclear Power Operations (INPO), and Duke Energy Corporation. Table 3 below provides a brief summary of the documents reviewed.

Table 3. Summary of reviewed procedure writing and adherence documents.

\begin{tabular}{|l|l|l|}
\hline \multicolumn{1}{|c|}{ Document Title } & Organization & \multicolumn{1}{c|}{ Brief Description } \\
\hline $\begin{array}{l}\text { Procedure Writer's Manual } \\
\text { (PPA AP-907-005, 2011) }\end{array}$ & PPA & $\begin{array}{l}\text { The PPA developed this manual to provide a nuclear } \\
\text { industry consensus standard for writing human factored } \\
\text { procedures. }\end{array}$ \\
\hline $\begin{array}{l}\text { Procedure Process } \\
\text { (PPA AP-907-001, 2011) }\end{array}$ & PPA & $\begin{array}{l}\text { This is a PPA document that provides a standard } \\
\text { process for creating and altering procedures. The } \\
\text { document is intended to be used by nuclear facility } \\
\text { owners and operators to assess their organization's } \\
\text { management of the procedure process, as well as to be } \\
\text { used as a tool for performing effective self-assessments } \\
\text { and benchmarking. }\end{array}$ \\
\hline
\end{tabular}




\begin{tabular}{|l|l|l|}
\hline \multicolumn{1}{|c|}{ Document Title } & Organization & \multicolumn{1}{c|}{ Brief Description } \\
\hline $\begin{array}{l}\text { Procedure Use \& } \\
\text { (INPS 09-004, 2009) }\end{array}$ & INPO & $\begin{array}{l}\text { This INPO document aims to provide an industry } \\
\text { guideline based on the experience and knowledge of } \\
\text { nuclear industry peers, factoring in the best available } \\
\text { human performance strategies, as well as provide } \\
\text { procedure use guidance based on the types of } \\
\text { procedures. It also provides guidance for adherence to } \\
\text { procedures by establishing principles, guidelines, and } \\
\text { rules. }\end{array}$ \\
\hline $\begin{array}{l}\text { Administrative Instructions } \\
\text { for Technical Procedures } \\
\text { (NSD 703, 2011) }\end{array}$ & $\begin{array}{l}\text { Duke Energy } \\
\text { Corporation }\end{array}$ & $\begin{array}{l}\text { This directive defines the processes that will be used in } \\
\text { the development and maintenance of technical } \\
\text { procedures within a nuclear power utility. }\end{array}$ \\
\hline $\begin{array}{l}\text { Technical Procedure Use } \\
\text { and Adherence } \\
\text { (NSD 704, 2011) }\end{array}$ & $\begin{array}{l}\text { Duke Energy } \\
\text { Corporation }\end{array}$ & $\begin{array}{l}\text { This utility directive provides guidance in the proper use } \\
\text { of and adherence to procedures and provides guidance } \\
\text { in the completion and approval of completed } \\
\text { procedures. }\end{array}$ \\
\hline $\begin{array}{l}\text { Procedure Writing Guide } \\
\text { (OSG, 2011) }\end{array}$ & $\begin{array}{l}\text { Duke Energy } \\
\text { Corporation }\end{array}$ & $\begin{array}{l}\text { The purpose of this utility procedure is to establish } \\
\text { guidelines for development, review, approval, and } \\
\text { changing of procedures for the operations group. }\end{array}$ \\
\hline
\end{tabular}

\subsubsection{Design, Development, and Review Guidelines for CBPS}

Researchers reviewed documents and standards that provide guidance on how to design CBP systems. The main documents reviewed were section 8 of NUREG-0700 (O'Hara et al., 2000) and the IEEE 1786 standard (IEEE, 2012). The review of these documents revealed that this guidance is tailored more toward control room procedures and may not be entirely applicable to field procedures. In many cases the guidance is on a high level and may not be adequate for someone seeking specific design guidance (which is a need that the researchers identified).

Based on the review of existing CBP research the team conducting this current effort concluded that the existing research do not sufficiently address areas such as design guidelines for automation and CBPs. Nor does the literature sufficiently address CBPs for field workers. There is a big gap between the existing literature and what is needed to address the nuclear industry's needs. The current research effort aims to minimize this gap.

\subsection{Qualitative Study}

The research team used the information gathered from the literature and the discussions (informal interviews) held with NPP personnel early in the research effort as a basis for designing the qualitative study to be conducted at a NPP. The qualitative study was conducted over 4 days and involved participants from four nuclear power utilities and five research institutes. The study consisted of three information gathering efforts: Observations, Interviews, and Focus Groups. The primary goal of the qualitative study was to develop a model of procedure use; secondary goals were to validate and refine the problem statement, develop an information flow diagram, determine the feasibility of some of the potential CBP solutions, and to identify requirements for CBPs. Section 3.5 discusses the development of the model of procedure usage and presents a description of the model. Figure 4 shows how the three efforts in the qualitative study supported the development of the model of procedure use. The study also 
aimed to identify requirements for CBPs and the mobile devices used by the field workers when using the CBPs.

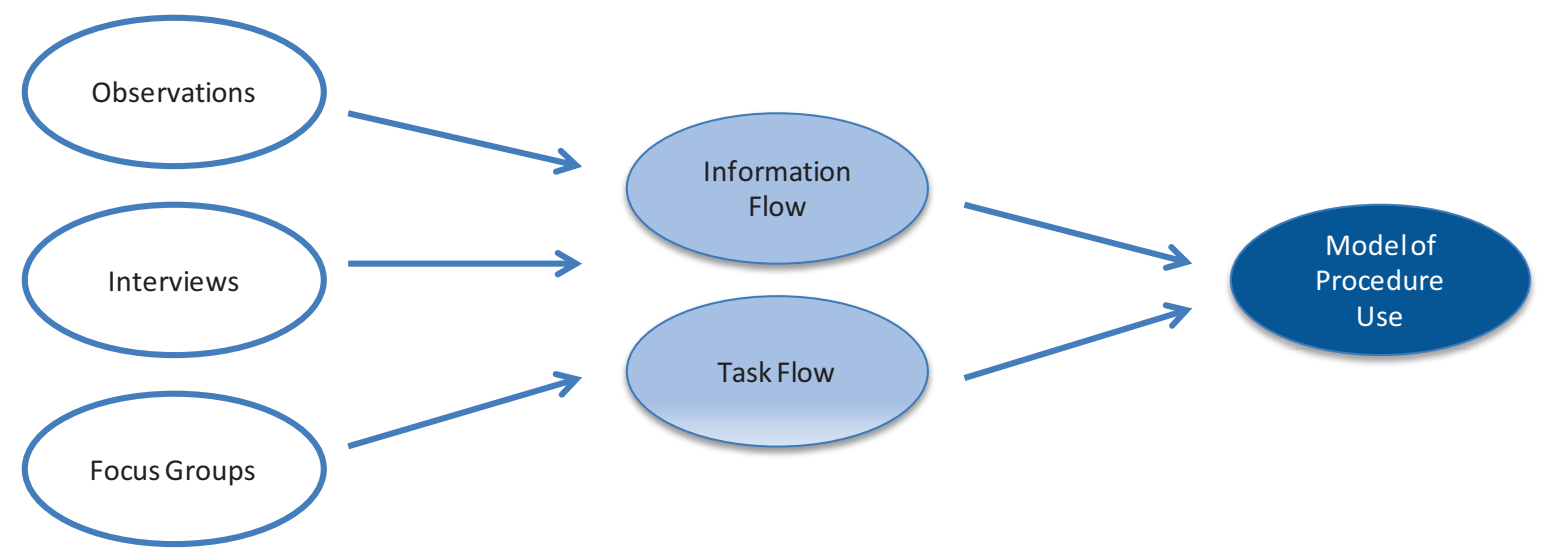

Figure 4. Activities conducted in the qualitative study.

\subsubsection{Field Worker Observations, Interviews and Focus Groups}

\section{Observations}

The research team observed individual turnovers, a shift brief, and pre-job brief. The researchers observed two field operators performing rounds. One operator performed his round in the turbine building and the other field operator made his round at the service building and the outside areas, including the cooling towers. The main types of information captured during the observations were 1) activities involved in the execution of a task, and 2) information related to communication and information flow while a task is executed. Appendix E provides a complete list of questions asked in the interviews and specific activities that were observed during this portion of the qualitative study.

\section{Interviews}

The researchers conducted 15 semi-structured interviews with field operators and maintenance technicians. Ten interviews were with field operators and five with maintenance technicians. One-half of the interviews with field operators were conducted in direct relation to the observations. All the remaining interviews were conducted throughout the 4-day study. The questions asked in the interviews aimed to address procedure use as well as procedure adherence. The researchers' goal was to gain a deeper understanding of what would cause the operator to deviate from the procedure, what would cause the operator to stop work and contact the supervisor, and what physical and cognitive functions are involved in the execution of a procedure steps.

\section{Focus Groups}

Focus group discussions were held throughout the course of the qualitative study. The purpose of the focus groups was to discuss how technology can support field workers as well as what functions are needed to make a CBP system useful for the field worker. The groups also discussed what type of mobile device would be most effective when executing a CBP in the field. Thirty-four people participated in the focus groups. Table 4 shows the distribution of organizations represented in the focus groups. The label "Other" includes people working with human performance, radiation protection, managers, and one representative from a technology vendor. As stated above, four nuclear power utilities and five research institutes participated in the study.

Insights from the focus group discussions included the need for a set of requirements and standards for CBPs, and the need to design CBPs in a manner that will to enhance human performance compared to PBPs. A CBP system that simply mimics PBPs and displays them on an electronic device would not be enough of an improvement to justify a migration to CBPs. Another important insight gained is utilities are 
reluctant to be the first one implementing CBPs. Utilities perceive the migration to CBPs to be risky because of a potential lack of regulatory buy-in for CBPs. However, this risk would be mitigated or at least more manageable if the industry as a whole moved forward with CBPs.

Table 4. Distribution of focus groups participants.

\begin{tabular}{|c|c|c|c|c|}
\hline Field Operations & Maintenance & IT Department & Research & Other \\
\hline $\mathbf{5}$ & 5 & 4 & 10 & 10 \\
\hline
\end{tabular}

\subsubsection{Mapping Task and Information Flow}

The purpose of the observations, interviews, and focus groups was to map the task flow and the information flow related to procedure use in the plant. The task flow aimed to identify work processes and mental processes involved in carry out procedure-driven tasks in the field. The goal of the information flow mapping exercise was to identify how information is transferred during the execution of a procedure-driven task. The questions asked were:

- Who receives information?

- Who is communicating the information?

- When is the information shared or received?

- Why is the information shared?

- Is the information communicated in written or verbal form?

Table 5 depicts both the initial map of information flow that the researchers had made based on early discussions with the collaborating utilities and the map of information flow developed based on the information gathered during the qualitative study. When the two maps are compared, it is apparent that the qualitative study provided a more detailed understanding of both work processes and information flow.

The initial map describes the process and information flow that occurs between the assignment of a task to a field operator and the execution of the task. The operator performs a job walk-down, he has a pre-job brief with his supervisor, and he checks with the control room to let them know that he is leaving to execute the task as well as to find out if there is any other work in progress. All of this must be conducted before he walks out to execute the task.

The researchers expected that this map was very simplified compared to reality; this expectation was confirmed during the observations and interviews at the NPP work site. A large amount of information is transferred between the different players involved in the work task, as shown in the second part of Figure 6. The research team endeavored to identify this flow of information as accurately as possible to understand how to best improve the process and reduce the risk of error prone situations within the process itself. 

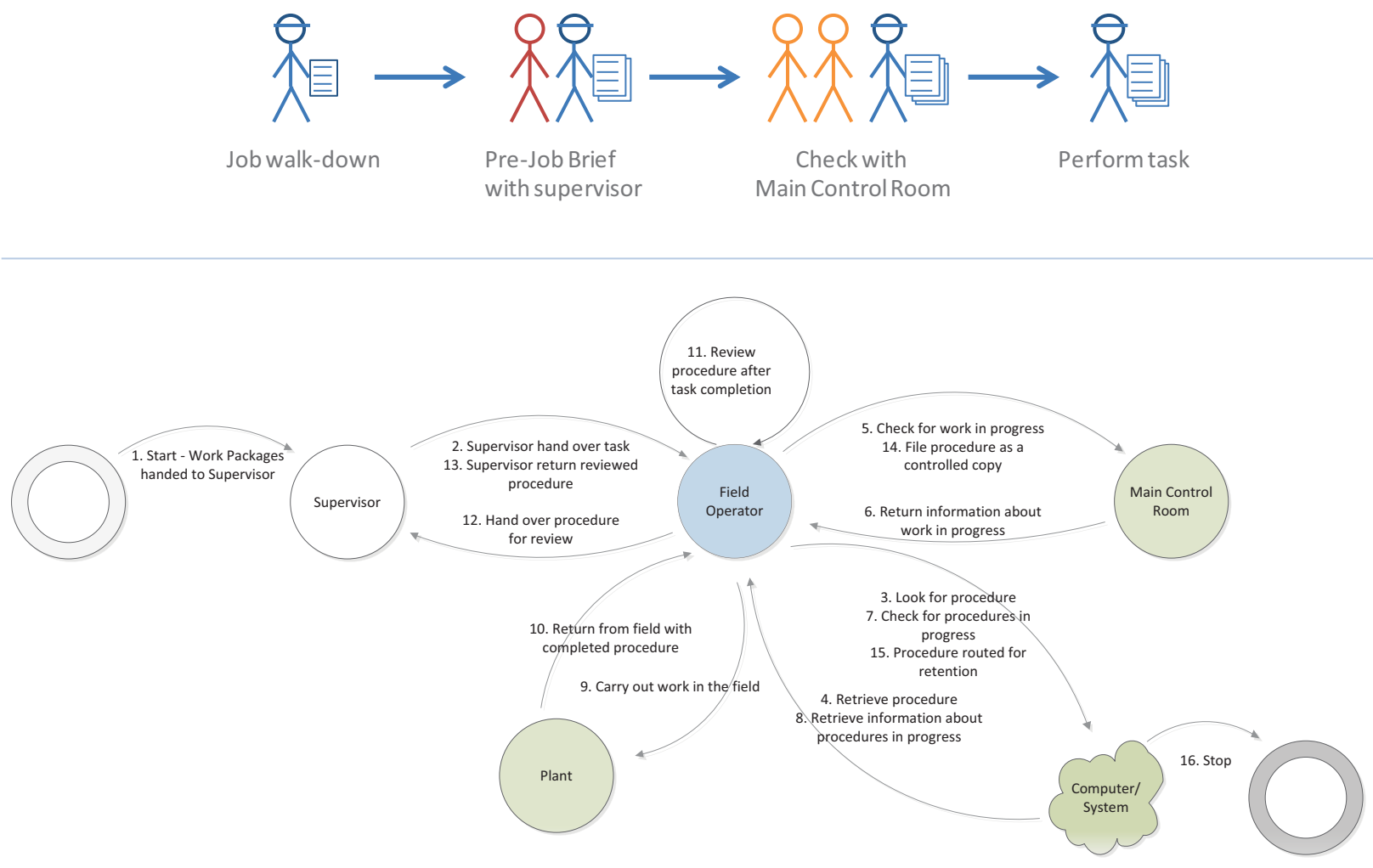

Figure 5. Initial and enhanced maps of information flow.

\subsection{User Needs Assessment}

The research team conducted a user needs analysis to gain a better understanding of the nuclear utilities' current plans for implementing CBPs, the current infrastructure in place to support CBPs, as well as the perceived or real barriers to implement CBPs systems. The focus groups discussions were the initial part of this analysis. To follow up on the information gathered in these discussions, a utility survey was conducted. The survey was distributed to 15 individuals representing six nuclear power utilities. The 10 questions in the survey (listed in Appendix F) addressed areas such as:

- Are CBPs in the utility's long-term vision?

- Is the utility considering CBPs for main control room operations, field operations, or both?

- What type of infrastructure does the plant have in place currently?

- What perceived barriers exist to implementing CBPs and what support do the utility need to overcome those barriers?

The survey included three different types of questions: (1) forced-choice yes/no questions, (2) multiple choice questions, and (3) free-form questions. The first two types provided an opportunity to quantify the answers, while the third type provided the necessary context.

The main finding was that there is substantial utility interest in implementing CBPs. All of the participating utilities reported that CBPs for field operators were part of their long-term vision. Sixty-six percent reported that CBPs for control room operators were in the long-term vision. The survey and its results are discussed in greater detail in the paper, Requirements for Computer Based-Procedures for Nuclear Power Plant Field Operators - Results from a Qualitative Study (Appendix C). 


\subsection{Model of Procedure Usage}

The research team could not identify an existing model of procedure usage in any of the research reviewed in during the literature review effort. The research team identified the lack of a detailed description of how the operator interacts with a procedure as one potential reason why the nuclear industry has found it difficult to apply the research to the real environment in the plant. As stated earlier, it is very important to understand the problem space, the real issues that must be resolved, and the research that must be done to make it applicable to the industry. One way of ensuring this is to investigate the potential problem in detail. Since the research hypothesis is that procedure use and adherence can be improved by phasing out PBPs in the favor of CBPs, it is important to gain a detail understanding of the current use of PBPs. The model of procedure usage is one major piece in gaining this understanding. A detailed understanding of the use of PBPs is needed to identify potential process improvements and reductions of the risk for human errors. One of the main goals of the qualitative study was to gather data needed to construct this model. The research team focused on work processes and procedures currently used at the utilities. Hence, the model of procedure usage reflects the use of PBPs and current work processes.

The purpose of the model is to identify the physical and cognitive actions involved in the execution of one procedure step as well as potential error traps and what factors affect the risk of these human errors. The paper Model of Procedure Usage - Results from a Qualitative Study to Inform Design of ComputerBased Procedures (Appendix A) presents the initial version of the model. This version contains a task flow and a set of factors that may contribute to errors. Based on result from continuous research and feedback from peer-reviews the model of procedure usage was revised. The development of the enhanced model is described in paper A Model of Operator Interaction with Field Procedures: Insights for Computer-Based Procedures (Appendix B). The enhanced model of procedure usage is also presented in Figure 6 on page 18. The enhanced model contains the following elements:

1. Detailed task flow in the execution of a single procedure step

2. Description of the techniques used to make decisions

3. Description of the conditions that must be satisfied to ensure task success

4. Description of the cognitive factors that influence the error likelihood.

The detailed task flow was constructed based on field operators' detailed descriptions of what actions they take when attempting to execute a procedure step. In the model of procedure usage, the detailed task flow illustrates the individual elements involved in the process of executing a single procedure step. This includes physical action steps such as locating the component and manipulation of it according to the procedure, as well as cognitive tasks such as the operator checks that he fully understands the step as written and that the plant's response to the action match the operators' mental model of the expected response.

The second part of the model of procedure usage is a description of the techniques used to make decisions outlined in the task flow. The techniques were identified based on the field operators' descriptions of exactly how they decide whether they can execute a procedure step as written. Examples of techniques are the comparison of actions to be taken according to the operator's mental model and the actual description in the procedure step, the comparison of expected conditions with actual conditions, and the comparison of component label and description in the procedure with the actual component in the plant.

The conditions that must be satisfied to ensure task success for each element in the task flow were identified by taking the operators' descriptions of situations in which they have made errors (or could have made errors) into consideration as well as evaluating decision techniques from a psychological and human factors perspective. Examples of conditions that must be satisfied are the need to have an accurate 
mental model that dictates expected conditions and the ability to correctly read procedure and equipment information.

The last part of the model of procedure usage is a description of the cognitive factors that influence the error likelihood for each element. This part was constructed by reviewing the current psychological literature for research that is relevant to the errors. Some of the cognitive factors identified are working memory, long-term memory, the salience of cues, and text comprehension.

The model of procedure usage is used by the research team both in the process of identifying requirements for CBPs and in the prototype development process. It is important that the error traps identified in the model are adequately addressed and that the cognitive load on the operator is reduced. The model will be continuously revised based on operator feedback and results from studies gathered throughout the span of the research effort. 


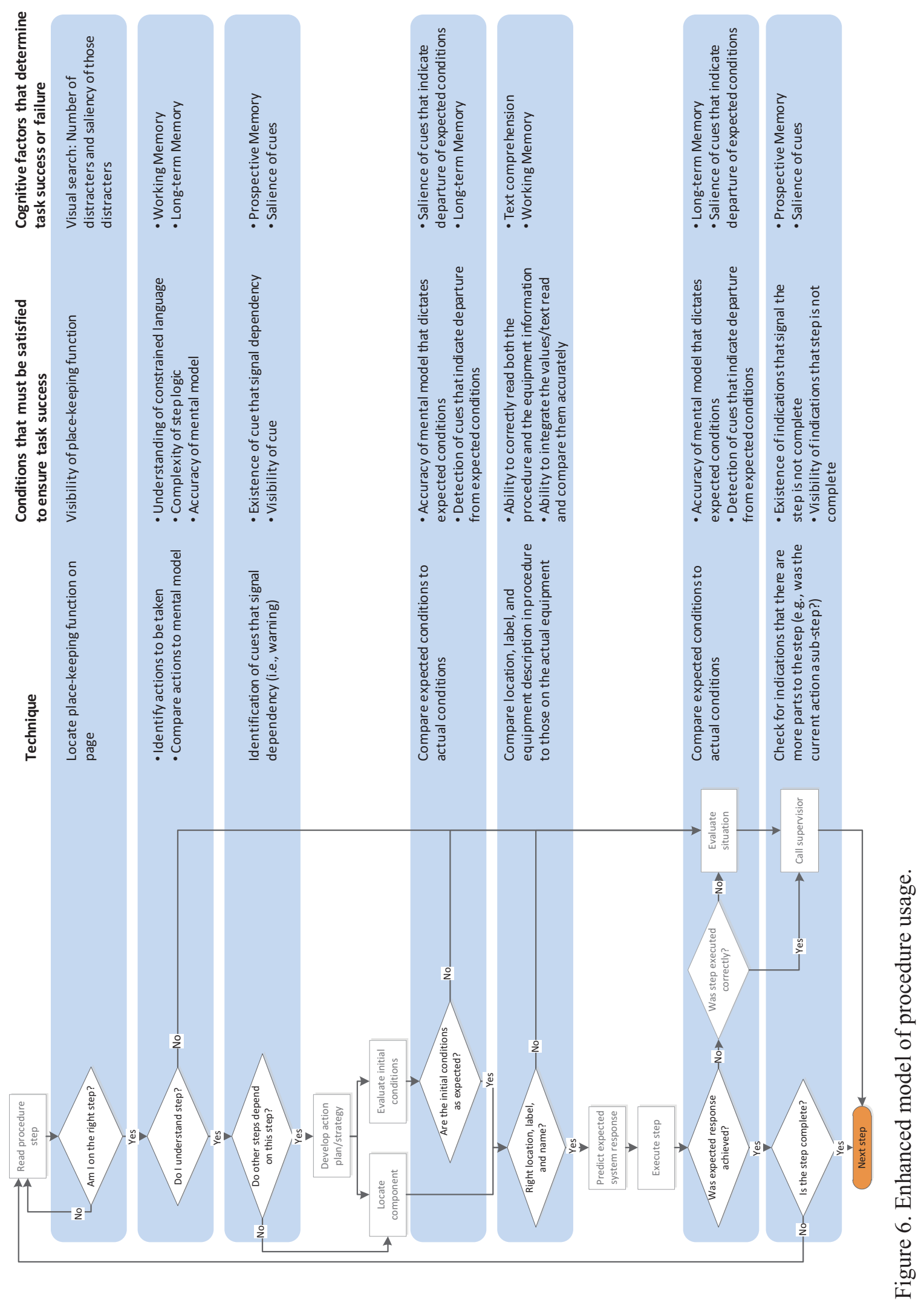




\subsection{Development of Requirements}

The research team developed a general set of requirements for CBPs for field operators; the identification, definition, and selection process was based on an analysis of the model of procedure usage and a review of basic psychological and human factors literature. The literature was reviewed to determine if the potential computer-based procedure solution may produce unintended consequences, such as increase the risk of errors by introducing additional interface management tasks. The requirements were selected based on the following criteria: (1) there is a clear and attainable solution for the potential error identified in the model of procedure usage, and (2) no negative consequences were identified related to the specific requirement. The list of requirements defined as a result of the qualitative study as well as the detailed description of each requirement are presented in Requirements for Computer Based-Procedures for Nuclear Power Plant Field Operators - Results from a Qualitative Study, Appendix C. Note that the requirements defined and presented here are not intended to be a complete set of requirements for CBPs. However, they are the minimum requirements needed to address the specific challenges indentified in the qualitative study. The identified requirements state that CBPs should:

1. Guide operators through the logical sequence of the procedure. The CBPs should be designed so that they automatically take the operators through the specified procedure path based on initial conditions and operator input.

2. Ease the burden of place-keeping for the operator. CBPs should keep track of where the operator is in the procedure, should mark steps as completed, and should highlight the current step.

3. Make the action steps distinguishable from information gathering steps. CBPs should use some method to differentiate steps for which an operator must actually manipulate the plant versus when he must simply check a condition or value.

4. Alert operator to dependencies between steps. Typically, the operator has to rely on previous experience or on a caution or warning in order to identify the situations in which he needs to read ahead in the steps. CBPs should alert the operator when he reaches a step with dependencies, rather than relying on him to read ahead (or remember from previous experience) to detect the dependency. Additionally, if a CBP system has access to realtime plant data the system should alert the operator when plant status changes in a manner that affects the operator's task.

5. Ease the burden of correct component verification for the operator. CBPs should employ some method to automate correct component verification (e.g., include barcode scanning or text recognition functionality).

6. Ease the identification and support assessment of the expected initial conditions. Some method of illustrating the expected initial conditions in a simple and easy to understand manner should be available to the operator through the CBPs. For example a schematic or piping and instrument diagram of the relevant equipment could be available on-demand.

7. Ease the identification and support assessment of the expected plant and equipment response. Some method of illustrating the expected equipment and plant response in a simple and easy to understand manner should be available to the operator through the CBPs. For example a schematic or Piping and Instrument diagram of the relevant equipment could be available on-demand.

8. Include functionality that improves communication. In the event that an operator encounters a situation that he needs to contact a supervisor to resolve, he needs to be able to efficiently and accurately describe the problem. Tools such as texting, capturing 
photographs and streaming video have all been identified as highly desirable to have built into any device that display CBPs.

The research team complemented the set of general requirements with a list of specific CBP requirements for field operators. This list of requirements was developed based on review of existing CBP guidance. The research team reviewed the following guidance documents with the purpose to produce the list: Section 8 of NUREG-0700 (O'Hara 2000), IEEE Standard 1786 (IEEE 2012) and an in-press NUREG/CR (Le Blanc, Gertman, Boring, \& Xing, in press). The team selected and adapted the requirements from the list of human performance issues identified in Le Blanc et al. (in press). The selection criteria for the requirements specific to CBPs for field operators were: (1) the issue addressed by the requirement is relevant to field operating procedures, and (2) the issue addressed by the requirement is not related to the use of soft controls. These criteria were selected based on the assumption that that field operating procedures are unlikely to have procedure-based automation. The reason for this assumption is that most of the equipment is operated locally and that it therefore is unlikely that CBPs for field procedures will include soft controls. The full list of CBP requirements specific for field operators is presented in Requirements for Computer Based-Procedures for Nuclear Power Plant Field Operators Results from a Qualitative Study, Appendix C. Examples of requirements on the list are the CBP should:

1. Be designed so that the operator controls the procedure pace.

2. Make calculations when the necessary information is available.

3. Alert users when procedure steps or conditions are at risk to be violated.

4. Alert users when conditions require transitioning to another procedure.

5. Evaluate step logic when the necessary information is available.

6. Be designed so that it is easy for the user to "undo" an unintended or incorrect action (an error of commission).

7. Allow the operator to look ahead and back in the procedure.

\subsection{Prototype Development, Testing, and Evaluation}

In the next phase of this research effort (starting April 1, 2012), the research team will develop prototypes of CBP user interfaces based on the results from the literature review and the qualitative study, which includes the model of procedure use and the identified requirements for CBPs. The results from the previous studies will help inform the selection of design concepts to implement and what specific issues related to procedure use and adherence to address. The prototypes will also be designed to test different functionalities that are of interest to investigate and evaluate. The development of the prototypes is an iterative process where user feedback from the collaborating utilities will be gathered and incorporated throughout the process. The feedback will be gathered through semi-formal user tests performed at the utilities. The research team may also conduct small-scale laboratory tests to bridge minor knowledge gaps that are identified during the qualitative study. Examples of such gaps are layout of a procedure step and the use of nomenclature in the procedure. These smaller studies will be conducted at the INL's research facility. Together with the collaboration partners, the research team will select one specific procedure to be implemented as a CBP. Some of the selection criteria are:

- The procedure is currently used by a field worker organization (field operations, maintenance, chemistry, etc.)

- The procedure is executed frequent enough that sufficient research data can be collected

- The procedure is executed in a location and on a system that can be observed by the research team.

In the fall of 2012, an evaluation study will be conducted at a nuclear power utility. The study will focus on the use of the $\mathrm{CBP}$ and the current PBP version of the selected plant procedure, and the 
comparison of the two. Field workers at the plant will be observed using both versions of the procedure. The purpose of the evaluation study is to compare the use and execution of the CBP to the current use and execution of the PBP version. The CBP's user interface design will also be evaluated in terms of usability, acceptability, and potential increased process efficiency.

The results from the evaluation study will be utilized in the discussion and decision of the path forward for the second year of the research effort. Together with the collaborating utilities, the research team will identify which issues to address next and what field worker organization to focus on. 


\section{SUMMARY OF RESEARCH PAPERS}

The development process of the model of procedure usage, the development of requirements, as well as both the literature review, and the qualitative study are documented in three research papers. The papers have been submitted to conferences. Table 5 lists the paper titles and the conferences to which they are submitted, as well as in which appendix the respective paper can be found.

Table 5. Publication Information.

\begin{tabular}{|l|l|c|}
\hline \multicolumn{1}{|c|}{ Title of Paper } & \multicolumn{1}{|c|}{ Conference } & Appendix \\
\hline $\begin{array}{l}\text { Model of Procedure Usage - Results from } \\
\text { a Qualitative Study to Inform Design of } \\
\text { Computer-Based Procedures }\end{array}$ & $\begin{array}{l}\text { 8th International Conference On Nuclear } \\
\text { Plant Instrumentation, Control, and } \\
\text { Human-Machine Interface Technologies } \\
\text { (ANS NPIC \& HMIT 2012) }\end{array}$ & A \\
\hline $\begin{array}{l}\text { A Model of Operator Interaction with } \\
\text { Field Procedures: Insights for Computer- } \\
\text { Based Procedures }\end{array}$ & $\begin{array}{l}\text { Human Factors and Ergonomic Society } \\
\text { 56th Annual Meeting (HFES 2012) }\end{array}$ & B \\
\hline $\begin{array}{l}\text { Requirements for Computer-Based } \\
\text { Procedures for Nuclear Power Plant Field } \\
\text { Operators - Results from a Qualitative } \\
\text { Study }\end{array}$ & $\begin{array}{l}\text { 3rd International Conference on NPP } \\
\text { Life Management for Long Term } \\
\text { Operations (IAEA PLiM 2012) }\end{array}$ & C \\
\hline
\end{tabular}

Figure 7 illustrates the relationship between the papers. Each paper is a progression of the previous one. The first paper, Model of Procedure Usage - Results from a Qualitative Study to Inform Design of Computer-Based Procedures, describes the literature review and the qualitative study in detail. The results from the studies informed the identification of requirements and the development of the initial version of the model of procedure use. This paper describes the construction of the model. In the process of identifying requirements, the researchers also identified additional areas related to procedure use that can be improved by CBPs. These areas are discussed as well. This paper has been submitted to the ANS NPIC and HMIT 2012 conference and is accepted and currently in press.

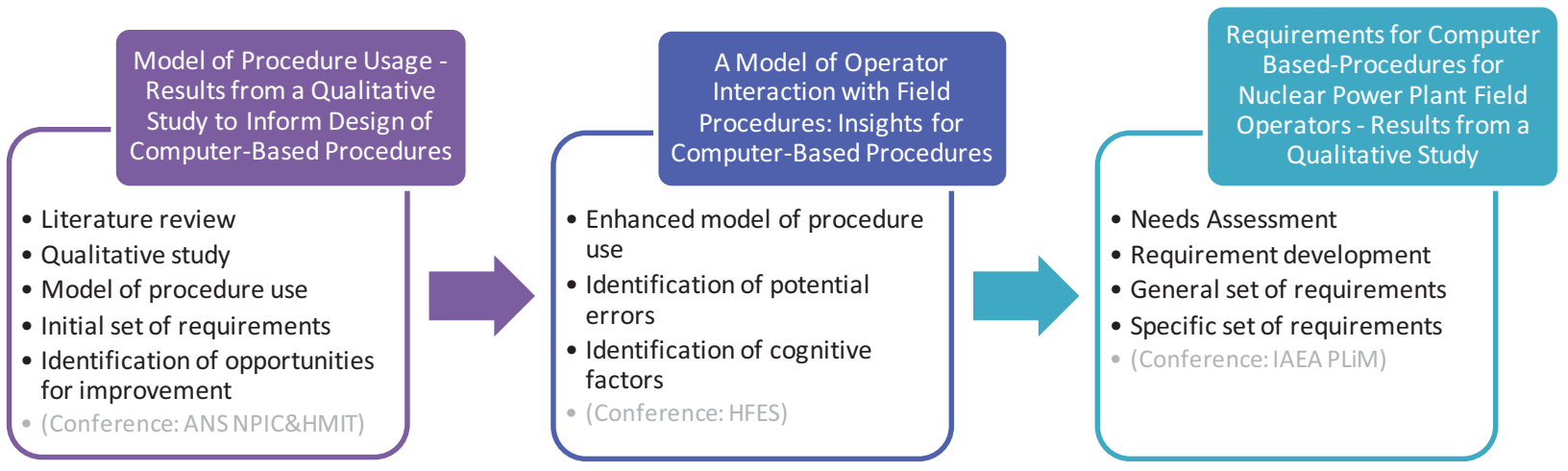

Figure 7. Relationship between publications

The second paper, A Model of Operator Interaction with Field Procedures: Insights for ComputerBased Procedures, describes the enhanced model of procedure use. The research team identified potential errors that can occur in the process of executing a procedure step. These potential errors, along with identified cognitive factors that affect the risk of error, were incorporated into the initial model and resulted in an enhanced version. This second paper is a proposal submitted to HFES 2012. The proposal is still under review. The third paper, Requirements for Computer Based-Procedures for Nuclear Power 
Plant Field Operators - Results from a Qualitative Study, focuses on the requirements for CBPs. These requirements have been identified throughout the literature review, the qualitative study, and a user needs assessment. They were also developed based on the model of procedure usage. This paper describes the user needs assessment and the process of requirement development. An initial set of the requirements was presented in the first paper. The work in which the third paper is based has refined the initial set of requirements. The updated version of the set of requirements is presented in the third paper. This paper has been submitted to the International Atomic Energy Agency (IAEA) PLiM conference and is currently in press. 


\section{CONCLUSION}

At the time of this report, the research effort is approximately half-way through its first year. The studies conducted to date are a literature review, a qualitative study, and a user needs analysis. The studies revealed the fact that, even though there are about thirty years of research in the field of CBPs, almost no research efforts have focused on CBPs for field workers. The user needs analysis identified that CBPs are an area that the nuclear industry is interested in and is actively pursuing. The use of PBPs has ensured a high level of safety and efficiency in the industry and it is believed that the use of CBPs will keep increasing these factors. In order to ensure this improvement of safety and efficiency it is important to ground the design of the procedure system and its use in human factors. Based on the data gathered in the studies conducted, the research team developed a model of procedure usage. The model's intended purpose is to provide a detailed understanding of the current use of procedures and the different opportunities for errors the operator faces daily. This detailed understanding is essential is the process of developing the user interface for a computer-based procedure system. It will ensure that important issues are adequately addressed and that positive features in the current work processes are not removed. The development of the model of procedure usage is an iterative process throughout the research effort. The model will be revised accordingly to match the research team's deeper understanding of the process of procedure execution.

Based on the studies and the model of procedure use, the research team developed two sets of requirements: (1) a general set of requirements for CBPs, and (2) a set of requirements specific to CBPs used by field workers. These requirements will be utilized in the next phase of the research effort, i.e. the development of design concepts and prototypes of CBPs. In the fall of 2012 an evaluation study will be conducted where the prototypes will be evaluated in both terms of functionality and usability. Even though the requirements presented in this report are not intended to be a viewed as a complete set of requirements for CBPs, they are still considered to be useful to the industry. This set of minimum requirements needed to address specific challenges related to procedure use and adherence is a significant advancement in CBP research for field workers. As the research effort progresses newly defined requirements for CBPs will be added to the existing list. 


\section{REFERENCES}

Byrd, K. S. and Caldwell, B. S. (2009). From UMPCs to Cell Phones: How Does Diminishing Screen Real Estate Affect Screen Access and Working Memory? Proceedings of the Human Factors and Ergonomics Society Annual Meeting, October 2009, 53: 960-964.

Byrd, K. S. \& Caldwell, B. S. (2011). "Increased Memory Load during Task Completion when Procedures are Presented on Mobile Screens." Taylor \& Francis Online. Vol. 20, Issue 5, 2011, pp. 643-658.

Chung, Y. H., Daihwan Min; Kim, B. R. (2002). Observations on emergency operations using computerized procedure system. Proceedings of the 2002 IEEE $7^{\text {th }}$ Conference on Human Factors and Power Plants, 4-61- 4-65.

Converse, S. (1995). Evaluation of the Computerized Procedure Manual II (COPMA II) (NUREG/CR6398). Washington, DC: U.S. Nuclear Regulatory Commission.

Duke Energy Corporation (2011). Technical Procedure Use and Adherence, Nuclear System Directive, NSD 704, Rev. 19, June 09, 2011.

Duke Energy Corporation Operations Management Procedure (OSG), Procedure Writing Guide, Rev. 23, September 02, 2011.

Duke Energy Corporation. (2011). Administrative Instructions for Technical Procedures, Nuclear System Directive, NSD 703, Rev. 31, November 01, 2011.

Huang, F-H. and Hwang, S-L. (2009). Experimental Studies of Computerized Procedures and Team Size in Nuclear Power Plant Operations. Nuclear Engineering and Design, 239, pp. 373-380.

"IEEE Guide for Human Factors Applications of Computerized Operating Procedure Systems (COPS) at Nuclear Power Generating Stations and Other Nuclear Facilities," IEEE Std 1786-2011 , vol., no., pp.1-38, Sept. 22 2011, doi: 10.1109/IEEESTD.2011.6029264.

INPO 09-004. (2009). Procedure Use \& Adherence, Rev. 0, INPO Good Practice.

Jeffroy, F., and Charron, S. (1997). From safety assessment to research in the domain of human factors: The case of operations with computerised procedures. Paper presented at IEEE 6th annual Human Factors Meeting, Orlando, Florida.

Jung, Y., Shin, Y., and Park, I. (2000). An Incremental Objective Achievement Model in Computerized Procedure Execution. Reliability Engineering \& System Safety. 70, pp. 185-195.

Lee, Y., Hwang, S., and Wang, E. (2004). Reducing cognitive workload of a computer based procedure system. International Journal of Human-Computer Studies 63, pp. 587-606.

Park, J. \& Jung, W. (2007). A study on the development of a task complexity measure for emergency operating procedures of nuclear power plants. Reliability Engineering \& System Safety.92 (8), pp. $1102-1116$.

Procedure Professionals Association. (2011). Procedure Process Description, PPA AP-907-001, Rev. 1.

Procedure Professionals Association. (2011). Procedure Writers' Manual, PPA AP-907-005, Rev.1. procedures are presented on mobile screens. Behaviour \& Information Technology, 30:5, pp. 643-658.

Roth, E. and O'Hara, J. (2002). Integrating digital and conventional human system interface technology: Lessons learned from a control room modernization program, NUREG/CR-6749. Washington, D.C.: U.S. Nuclear Regulatory Commission. 
Xu, S., Song, F., Li, Z.Z., Zhao, Q.Y., Luo, W., He, X.H., and Salvendy, G. (2008). An ergonomics study of computerized emergency operating procedures: presentation style, task complexity, and training level, Reliability Engineering and System Safety, 93 (10), pp. 1500-1511. 


\section{Appendix A}

\section{Model of Procedure Usage - Results from a Qualitative Study to Inform Design of Computer-Based Procedures}




\title{
Appendix A
}

\section{Model of Procedure Usage - Results from a Qualitative Study to Inform Design of Computer-Based Procedures}

\author{
Authors \\ Katya Le Blanc \\ Johanna Oxstrand \\ Thomas Waicosky \\ Submitted to \\ 8th International Conference on Nuclear Plant Instrumentation, Control, and Human-Machine Interface \\ Technologies (ANS NPIC \& HMIT 2012)
}

Abstract accepted

December 29, 2011

Full paper submitted

March 15, 2012

Paper accepted

April 23, 2012

Conference dates

July 22-26, 2012 


\title{
Model of Procedure Usage - Results from a Qualitative Study to Inform Design of Computer-Based Procedures
}

\author{
Katya Le Blanc and Johanna Oxstrand \\ Idaho National Laboratory \\ Battelle Energy Alliance \\ P.O. Box 1625 \\ Idaho Falls, ID 83415-(3605) \\ katya.leblanc@inl.gov; johanna.oxstrand@inl.gov \\ Thomas Waicosky \\ Duke Energy Carolinas, LLC \\ CT01A / 4800 Concord Rd. \\ York, SC 29745 \\ thomas.waicosky@duke-energy.com
}

\begin{abstract}
The nuclear industry is constantly trying to find ways to decrease the human error rate, especially the human errors associated with procedure use. As a step toward the goal of improving procedure use performance, researchers, together with the nuclear industry, have been looking at replacing the current paper-based procedures with computer-based procedure systems. The concept of computerbased procedures is not new by any means; however most research has focused on procedures used in the main control room. Procedures reviewed in these efforts are mainly emergency operating procedures and normal operating procedures. Based on lessons learned for these previous efforts we are now exploring a more unknown application for computer based procedures - field procedures, i.e. procedures used by nuclear equipment operators and maintenance technicians. The Idaho National Laboratory and participants from the U.S. commercial nuclear industry are collaborating in an applied research effort with the objective of developing requirements and specifications for a computer-based procedure system to be used by field workers. The goal is to identify the types of human errors that can be mitigated by using computer-based procedures and how to best design the computer-based procedures to do so. This paper describes the development of a Model of Procedure Use and the qualitative study on which the model is based. The study was conducted in collaboration with four nuclear utilities and five research institutes. During the qualitative study and the model development requirements and for computer-based procedures were identified.
\end{abstract}

Key Words: Computer-Based Procedures, Field Operators, Nuclear Power Industry

\section{INTRODUCTION}

The commercial nuclear power industry is a complex, high-risk work environment. In order to manage that complexity and to ensure safety, most work activities in the nuclear industry are guided by procedures. These procedures are used to direct main control room operators, field operators, and maintenance personnel. Currently, procedures are typically presented and maintained on paper. While these paper-based procedures (PBPs) are viewed as necessary to manage human performance in the nuclear power industry, they have also been identified as potential contributors to human error. Many of the challenges associated with the use of PBPs are attributed to the fact that they are static, and do not necessarily reflect actual plant conditions (Fink, Killian, Hanes, \& Naser, 2009, O'Hara et al., 2000). Additionally, managing multiple procedures, place-keeping, and finding the correct procedure can be challenging with paper-based systems (Fink et al., 2009, Converse, 1995). 
Plans to upgrade existing plants with digital equipment and wireless technology provide an opportunity to enhance procedures by transforming the existing PBPs to computer-based procedures (CBPs). CBPs are not a new concept; they have been investigated as a potential solution to many of the challenges associated with PBPs since the early 1980s (Fink et al., 2009). However, most of those efforts have focused on normal and emergency operating procedures used in the main control room. Even though the focus has been on control room operating and emergency procedures, very few plants have implemented a computer-based system for these procedures. This is mainly due to the amount of regulation and scrutiny that applies procedures in the control room. Recent work has suggested that CBPs may be a viable option for enhancing human performance for field operators (Farris \& Oxstrand, in press).

Currently, the Idaho National Laboratory (INL) and participants from the U.S. commercial nuclear industry are collaborating in a research effort to explore CBPs for field workers including field operators and maintenance technicians. This application of computer-based procedures is relatively unexplored. However it might prove to be easier for the industry to make the transition from PBPs to CBPs for field procedures than for procedures used in the control room. This is due to the fact that these procedures are not as strictly scrutinized by the regulatory body as control room emergency procedures. CBPs for field workers can show that performance can be improved by CBPs, which will provide a justification for enhancing control room procedures in the future. This research effort and collaboration aims to identify a common vision for CBPs across the nuclear industry, and to help define a path forward for implementing CBPs starting with procedures for field operators.

As an emerging alternative to PBPs, CBPs could potentially increase reliability, efficiency, and safety at the plant by reducing operator workload and reducing the rate of human errors. CBPs could include features such as automatic place-keeping and integration of plant status information. Additionally, operational experience and just-in-time training could be incorporated into the procedures. Clearly, CBPs have great potential; however, a poorly designed CBP system could have negative effects on both human and plant performance. In order to avoid unintended and potentially negative consequences for human performance, thorough human factors research has to be conducted to build the theoretical and technical basis for the system design.

In order to understand how procedure performance can be improved with CBPs, it is important to first understand how current paper-based systems are actually used in the field. Identification of how procedures support the operators and technicians in their everyday tasks as well as identification of where additional support is needed is an important first step in defining the requirements for CBPs. It is also essential to identify areas where the computer-based procedures could help improve the process and hence improve human performance. To accomplish this, the focus should be on what features from the use of paper-based procedures should be kept, what should features should not be incorporated and what new features or work processes should be added to CBPs. The researchers from INL collaborated with four U.S. nuclear power utilities and five research institutes to conduct a study aimed at identifying the actual use of procedures as well as factors that contribute to both intentional deviations and unintentional errors in the procedure following process. The research effort also identified desirable features to be incorporated in the computer-based procedure system, and used the information gathered to develop an initial model of procedure usage. This model will be the basis for development of concepts and prototypes in the next stage of the research effort. This paper describes the study, the construction of the model of procedure use, and the requirements identified so far.

\section{METHOD}

The study consists of three main parts: 1) benchmark previous research and existing literature on CBPs; 2) develop a problem statement; and 3) gather information during a plant visit to inform a model of paper-based procedure usage and develop of requirements for CBPs (the qualitative study). 


\subsection{Benchmark Literature on CBPs}

The first step in the study was to benchmark previous research and existing literature on CBPs. The majority of research conducted on CBPs has focused on procedures used in the main control room. However, some guidance documents reviewed included field operating procedures in their scope (e.g., IEEE, 2011; O'Hara et al., 2000). Additionally, some recent work has investigated the potential use of technology to improve field workers' work processes in the nuclear industry (Farris \& Oxstrand, in press). Results from that research (derived from surveys and focus group discussions) were considered and incorporated into our problem statement and hypothesis. The specific insights that were applied to the current research effort were:

- Correct component verification (CCV) was indicated to be one of the most error-prone tasks for field operators and maintenance technicians

- Field operators and maintenance technicians need to have maximum mobility (they often need to climb ladders, crawl through tight spaces, etc.) and should not be burdened with multiple devices

Finally, documents from both the Institute for Nuclear Power Operations (INPO, 2009) and nuclear power utilities related to procedure use and adherence as well as documents related to human performance were also reviewed as a part of the benchmarking exercise.

\subsection{Defining the Problem Statement}

The results from the benchmarking step fed into the development of an overall problem statement. The problem statement was verified by plant personnel at two utilities to ensure that it was consistent with industry concerns related to procedure use.

Problem statement: Numerous events and subsequent corrective actions are attributed to procedural use and adherence issues in nuclear power plants. The paper-based procedures currently utilized pose challenges in that they are static while actual plant conditions are dynamic. Therefore, the procedures may include sections or steps not applicable to the current situation as well as cautions or warnings that are misleading or confusing given the current plant status. These issues are all known to lead to unintended or erroneous actions.

Figure 1 illustrates the issues identified in the problem statement. Essentially, there are two global gaps in the ability of procedures to support operators in accomplishing their particular goal. The first gap (Gap A) occurs because procedures can only be written for anticipated situations. Unanticipated events or conditions may cause the plant state to be outside the scope of written procedures. CBPs can do little to close Gap A. The second gap (Gap B) illustrates the gap between how a procedure was intended to be used and what actually happens. For most procedural tasks, Gap B is non-existent (meaning that the intended use matches the actual use) however, intentional deviations from procedures (e.g., workarounds) as well as unintended errors may occasionally widen the gap. The main objective of qualitative study was to identify the factors that contribute to both intentional deviations and unintentional errors in the procedure following process.

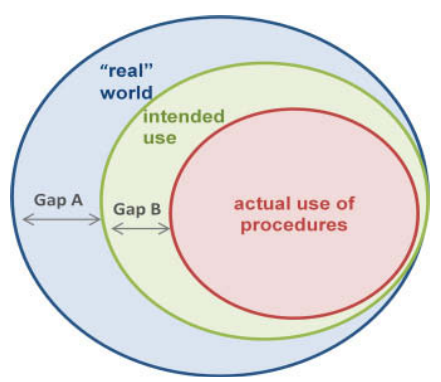

Figure 1. Relationship between reality, intended procedure use and actual procedure use 


\subsection{Qualitative Study}

The qualitative study was conducted during a plant visit and consisted of three data gathering activities: 1) On-the-job observation of field operators, 2) Structured interviews, and 3) Participation in focus group discussions.

The duration of the plant visit was four days. It was conducted at the same time as another research effort that demonstrated a prototype of how technology could be used to improve human performance in the field.

\subsubsection{Observation of field operators}

The researchers observed a shift turn-over including individual turn-overs and a shift brief. They also observed two field operators conducting rounds. The researchers were able to observe how the operators were using Personal Digital Assistants (PDAs) as a tool during their rounds guiding them to components to inspect and values to record. Researchers recorded the following information in their observations:

1. A timeline of the tasks the operator executed

2. Answers to the following questions about information flow

a. What information is needed in the field?

b. When is it needed?

c. How is it presented? Is it committed to memory?

d. Who needs it?

e. How is information communicated?

f. What information is needed in parallel?

The operators also volunteered some information regarding conditions and factors that contribute to errors in their everyday tasks during the observation. Those comments were also recorded.

\subsubsection{Interviews of field workers}

The researchers conducted semi-structured interviews with ten field operators and five maintenance technicians. One-third of the interviews were conducted in relation to the observations and the remaining interviews were conducted throughout the week that the researchers spent at the plant and in the plant's training facility. The researchers asked the following questions in order to develop the model of procedure use:

1. What are the most common reasons for deviating from a procedure?

2. During a typical procedural task, do you have the overall goal of the procedure in mind, or are you focused on executing the current step?

3. When executing a procedural action, do you feel you understand the consequences of that action on the plant?

4. What kind of things would cause you to stop and question whether you can complete a procedure as expected/written?

5. Can you walk me through the process of following a procedure step? What are the subtasks of following a procedure step?

6. On a typical day, how often do you consider stopping the procedure because you are unsure, but ultimately decide not to and go ahead with the procedure? What are your reasons?

7. What kind of information/criteria do you use to decide whether you need to stop and contact a supervisor?

The researchers also came up with several ad hoc questions they needed to ask in order to better understand how CBPs could improve work processes

\subsection{3. $\quad$ Focus groups}

Thirty-four people participated in focus groups that were conducted during the course of the week. Table 1 shows the distribution of the participants in the focus groups. Four nuclear power stations and five research institutions were represented. The group labeled 'Other' consisted of people working with human 
performance, radiation protection, managers, and one representative from a technology vendor. The purpose of the focus groups was to discuss how technology can support workers in the field and what is needed from a computer-based procedure system in order to be useful for the field operators and maintenance technicians.

Table 6 - Distribution of Focus Group Participants

$\begin{array}{ccccc}\text { Field Ops } & \text { Maintenance } & \text { IT } & \text { Researchers } & \text { Other } \\ 5 & 5 & 4 & 10 & 10\end{array}$

The study also focused on identifying requirements for the computer-based procedure system as well as the device the field workers would use to access the procedures. Items such as usability, user-interface, software features, and practical issues such as size and how to carry the device were addressed.

\subsubsection{Development of model of procedure use}

The qualitative data gathered during the observations, interviews, and focus groups informed the mapping of the flow of information and the use of procedures and work processes. Specifically, the operators responses to the questions presented in section 2.2.3 were used to build a task flow for executing a procedure step (i.e., the model of procedure usage), and to develop the factors that contribute to errors.

\section{RESULTS}

\subsection{Task Flow}

The first step in developing the model of procedure usage and requirements for CBPs was identification of task flow for all of the tasks an operator completes in a typical day. The primary purpose of identifying the task flow was to understand what an operator does to prepare for a job before he goes out into the plant and actually executes a procedure. A secondary purpose was to identify the information that an operator needs to perform a procedure. The task flow was constructed using the structured observation of operators on-the-job. Input from structured interviews was also included to fill in any elements not identified in the observations. In developing the task flow, the following elements were considered:

- The timeline of tasks and subtasks completed in an operator's typical work day

- The information the operator needs to complete those tasks, where that information comes from, and how it is presented

- The tools and equipment the operator uses to complete those tasks (e.g., paper procedures, flashlight, measuring tape, etc.)

The overall task flow included all activities a field operator would execute including individual shift turnovers, shift briefs, rounds, and procedures.

In developing the task flow, the researchers concluded that the steps an operator takes to prepare for executing a procedure can vary greatly depending on several factors including the level of risk associated with the task, the frequency of the task, and the complexity of the task. Therefore it is difficult to define a generalized task flow for procedure execution. However, for all tasks, an operator spends some time reviewing the procedure and some time reviewing any potential errors that may occur in the execution of the procedure. Therefore, before an operator goes out into the plant, he should understand the goals of the procedure and the effect it should have on the plant. 
Generally, after being assigned to a task the operator reviews the printed procedures needed to execute the task. This review is called a task preview or job walk-down. The operator reads the procedure and makes sure he understands the steps involved, the potential risks and hazards, and how to mitigate error-prone situations. The operator might at times conduct a physical walk-down, i.e. visit the task site to gain a better understanding or the environment and equipment involved. When the operator feels confident he has a good understanding of the task, he and other operators involved will conduct a pre-job brief. The purpose of the brief is to ensure that all risks are identified, all necessary preparations have been taken, and to discuss the supervisor's expectations. The operators also share and discuss previous operational experience related to the task. Before heading to the work site the operator checks with the main control room that the prerequisites are met and that no other work is in progress that would affect the task at hand (and to ensure that the work in the field will not affect anything that is being done in the control room).

If everything is clear, the operator heads out to the field and performs the task. In general, the only information that an operator takes out into the plant with him to execute a procedure is the procedure itself (although, depending on the task, he may also have equipment drawings). The operator relies on his memory for the rest of the information he has gathered in preparation for the task (e.g., information contained in the pre-job brief).

\subsection{Construction of Model of Procedure Usage}

Though researchers considered all work activities in the task flow, the focus of this portion of the research is how operators interact with procedures. Procedures are designed to guide operators through complex tasks. In a perfect world, procedures would cover all possible situations and operators would be able to follow procedures exactly as written. In reality, procedures cannot cover all possible situations, and operators must make judgments as to whether they are in a situation that is outside of the scope of the procedure. The criteria by which operators make these judgments are dictated by the procedural adherence standards adopted by the organization and by their own knowledge, experience and training. In situations where the procedures do cover the current situation perfectly, limitations in human perception and cognition make it possible for human operators to make errors in executing a procedure even when they intended to take the actions specified in the procedure.

In order to understand what errors can occur in execution of a procedure and how to mitigate them, it is necessary to understand the processes involved in following a procedure. Unfortunately, the process of following a procedure is more complex than simply reading a step and then executing it. There are several elements that an operator must go through in order to complete something as simple a single procedure step. Based on their observations and interviews, the researchers developed a model of the elements that an operator goes through in the process of following a procedure. The researchers chose the execution of a single procedure step as the scope for the model of procedure usage because at that level, it is possible to break down the process into the specific elements that an operator goes through in order to execute the step.

\subsection{Model}

Figure 2 illustrates the simplified process of following a single procedure step. Please note that even though most of the elements in the model are presented in a linear flow, some of the elements may be executed in parallel, or reiterated. Also note that this model represents a general and ideal flow of the elements that go into procedure step execution. Some of the elements may not apply in a particular situation or they may be unintentionally omitted by the operator. Also illustrated in Figure 2 is a brief description of the factors that contribute to errors that occur in each of the elements in the procedure following process. These were identified by operators or researchers based on interviews and observations. The factors are discussed in detail in section 3.4.1. 


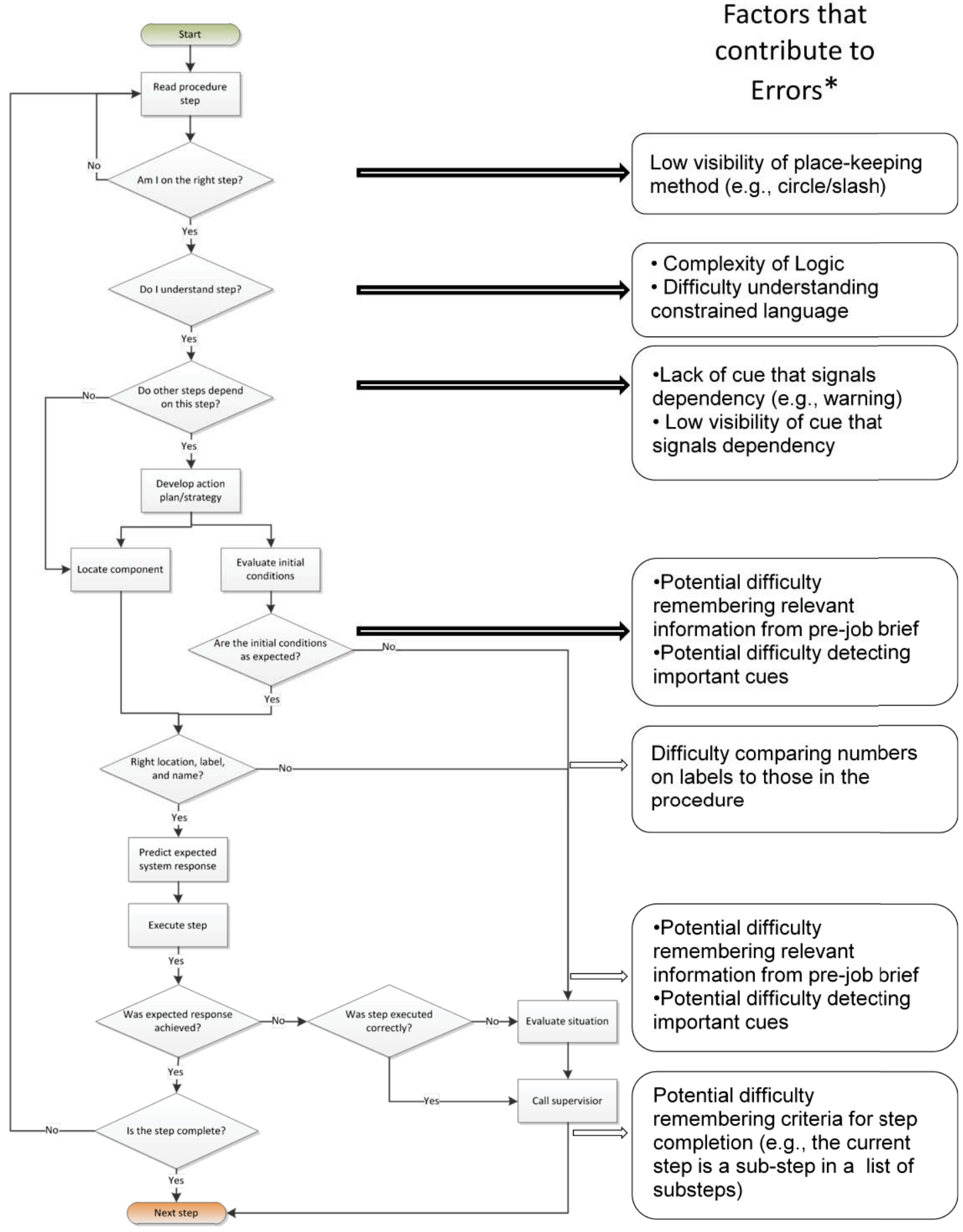

*This is not meant to be an exhaustive list of factors contributing to errors, it is simply a specific list of factors that were developed based on the qualitative study

Figure 2. Model of Procedure Usage and Accompanying Error-contributing Factors 


\subsection{Develop Requirements for CBPs}

\subsubsection{Analysis of the model of procedure usage}

The development of requirements was based on an in-depth analysis of the model of procedure usage. In this analysis, researchers identified the elements of procedure step execution that are particularly error-prone and which could be improved by the used of CBPs.

The elements identified as error-prone in the model of procedure usage help to illustrate the points in the procedure-following process where operators may need to make subjective judgments about whether the procedure is going as expected. These judgments are based on many sources of information including, the instructions in the procedure itself, the pre-job briefs and walk-downs, the operator's training and experience, and equipment response, as well as the operator's comfort in stopping and asking for help. It's important for an operator to feel safe in asking for help. Additionally by examining the model of procedure usage it is possible to determine where errors could occur and identify potential solutions that might be implemented with CBPs. Each of the error-prone elements is discussed below.

Am I on the right step? Before executing any procedural action, the operator has to make sure he is on the correct procedure step. This includes checking that no prior steps are unintentionally omitted. This is typically done with place-keeping protocols. Many plants use the "circle-slash" approach to placekeeping in procedures. When a step is started, the operator draws a circle near the step, when a step is completed the operator draws a slash through the circle. One other approach is to make the operators sign their initials by each step. A current trend is to make the operators use both approaches, i.e. circle the step when it is initiated, slash through the circle when completed, and finally sign initial by the slashed circle. While these methods are generally effective, the burden of place-keeping can still be quite large. There is a risk of forcing the operators to focus more on the secondary tasks and processes (i.e., place-keeping and initialing) than the primary task (i.e., actually manipulating the equipment). This can potentially lead to reduced awareness of the environment and situation, and hence lead to an increased human error rate.

Do I understand the procedure step? One of the most common difficulties in understanding procedure steps is correctly identifying the meaning of the constrained language used in the procedure. That is, some steps imply taking action on equipment (e.g., open and ensure) while others do not allow for action (e.g., verify). Further, if a step states that a valve should be opened, but it is already opened, operators are instructed not to simply move on in the procedure. An operator may read the step, and mistakenly think that he should open a valve, when it simply says to verify that the valve is open. Misidentification of the actions that are to be taken (or not taken) in a particular step is one cause of operator errors. Even if an operator correctly identifies the action to be taken on the initial reading of the step, some time may elapse between reading the step and executing the step. As seen in the model above, there are also several elements in the process of following a procedure that may occur between reading a step and executing it. The operator may misremember the action he is supposed to take by the time he actually executes the step.

Another issue related to understanding of the procedure step is the step logic can sometimes be cognitively demanding to process (e.g., If this, and that, then do x). Finally, a large portion of the text in a procedure step is devoted to long sequences of numbers and letters to identify equipment (tag, location, etc.). While these tags are absolutely necessary for CCV in PBPs, they may obscure the actual meaning of the procedure step, potentially contributing to errors.

Do other steps depend on this step? In many cases, an operator needs to know what steps are coming up in the procedure because the subsequent steps either need to be executed quickly or they need to be executed based on some condition that occurs after executing the previous step. In some cases, there is a caution or warning alerting the operator to that type of situation. Operators also tend to read ahead several steps to check for this situation. However, in some cases operators may omit this element the procedure following process and therefore execute a subsequent step too late or incorrectly. This is especially likely 
in situations where there is no warning or when the dependent steps appear on the following page. Another situation when dependencies may occur is in "When/Then" steps. There are cases when operators can proceed in a procedure past a "When/Then "step and when the stated conditions are met, the operator must go back to perform that step. CBPs that have access to real-time plant data can inform the operator when he or she needs need to perform this type of step.

Are the initial conditions as expected? Before executing a step, the operator must assess the surroundings to verify that the initial conditions are what is expected based on current plant status, ongoing work/procedures, equipment status, and so on. Much of the information that goes into this assessment must come from the operator's memory (from training, previous experience, the shift brief, pre-job brief and/or walk-down, etc.). The operator may not remember pertinent details, or he may be unaware of them. Therefore, the operator might make incorrect assumptions based on an incomplete understanding of the situation. The operator may also risk conducting an incomplete check to see if the initial conditions are as expected.

Right Location, Label, and Name? (i.e., am I on the right component?) CCV was identified as one the most error-prone elements in executing a procedure. The operator must locate each component among a sea of very similar components. Complicating matters is the fact that components for different systems may be located next to one another and have very similar labels (e.g., MFW-11A for train A and MFW11B for train B). Because of the way that humans process text (i.e., holistically), it is possible for even the most highly trained, diligent operator to misread a label and manipulate the wrong component.

Was the Expected Response Achieved? The operator has to assess the surroundings prior to the step execution as well as after the execution to ensure that the conditions are as expected. After the step execution the operator needs to assess if the plant responded in the manner that match both his understanding of the situation and what is described in the procedure. The operator uses visible, tactile, and/or audible cues to assess the plant response. If the operator has an incorrect understanding of the task at hand or of the current plant situation there is a risk that he will not identify an unexpected plant response.

Was the Step Executed Correctly? If the operator identifies an unexpected response after executing the procedure step he will have to go back to the procedure to check that the step was executed correctly. The operator will have to assess the situation and back-track his actions in order to conclude if step was executed correctly or not. If the operator's perception of how the step should be conducted do not match the actual writing in the procedure (e.g., due to a recent procedure revision) there is a risk that the operator will not correctly identify his own deviation.

\subsubsection{Requirements for CBPs}

Analysis of the model of procedure usage identified several elements in the process that are particularly error-prone. Many of these issues have clear, attainable solutions in the domain of CBPs. The researchers developed a list of requirements based on those issues and the potential solutions. They are discussed briefly below. Some of the requirements developed in this research effort are similar to guidance put forth in IEEE 1786 (IEEE, 2011) and O'Hara (2000), however the intent is different. The following list defines features of CBPs that are essential if they are going to improve human performance compared to PBPs (i.e., a CBP system without these features is unlikely to be successful in supporting operators).

1. CBPs should Guide Operators through the logical sequence of the procedure. The CBPs should be designed so that they automatically take the operators through the specified procedure path based on initial conditions and operator input.

2. CBPs should ease the burden of place-keeping for the operator. CBPs should keep track of where the operator is in the procedure, should mark steps as completed, and should highlight the current step. 
3. CBPs should make the action steps more distinguishable from information gathering steps. CBPs should use some method to differentiate steps for which an operator must actually manipulate the plant versus when he must simply check a condition or value

4. CBPs should alert operator to dependencies in steps more visibly. Typically, the operator has to rely on previous experience or on a caution or warning in order to identify the situations in which he needs to read ahead in the steps. CBPs should alert the operator when he reaches a step with dependencies, rather than relying on him to read ahead (or remember from previous experience) to detect the dependency. Additionally, if a CBP system has access to real-time plant data the system should alert the operator when plant status changes in a manner that affects the operator's task at hand.

5. $C B P$ s should ease the burden of $C C V$ for the operator. CBPs should employ some method to automate $\mathrm{CCV}$ (e.g., include barcode scanning or text recognition functionality).

6. CBPs should ease the identification and support assessment of the expected initial conditions. Some method of illustrating the expected initial conditions in a simple and easy to understand manner should be available to the operator through the CBPs. For example a schematic or piping and instrument diagram of the relevant equipment could be available on-demand.

7. CBPs should ease the identification and support assessment of the expected plant and equipment response. Some method of illustrating the expected equipment and plant response in a simple and easy to understand manner should be available to the operator through the CBPs. For example a schematic or Piping and Instrument diagram of the relevant equipment could be available ondemand.

8. CBPs should include functionality that improves communication. In the event that an operator encounters a situation that he needs to contact a supervisor to resolve, he needs to be able to efficiently and accurately describe the problem. Tools such as texting, capturing photographs and streaming video have all been identified as highly desirable to have built into any device that display CBPs.

\subsubsection{Opportunities}

In addition to the requirements developed above, the researchers identified several areas that can potentially be improved with CBPs, but which may introduce unintended consequences. These issues need to be researched thoroughly before they are implemented into CBP systems

Improve understandability of procedure steps. As mentioned above, much of the text in a procedure step is devoted to sequences of letters and numbers used to help identify the component. With CBPs it is possible to make this information available on-demand so that it does not obscure the instructions. Additionally, this information might not be needed as often with the use of barcode scanning for CCV. It is also possible to make the make the logical flow of the procedure steps more transparent. For example: If, then steps could be presented as two steps

- Is desired condition met?

- Execute desired action.

Similarly, it is possible to explicitly present the logic of the constrained language in the procedure text. For example, "ensure Valve A is open" could be broken into two possible steps

- Is valve 'A' open?

- If the response in "no" then the procedure would prompt the operator to open the valve

Improve tailoring of procedures to match plant status. Because paper-based procedures are static and the plant is dynamic, they are designed to cover a wide variety of conditions and situations. For example, there are often built-in contingencies for equipment that is out of service; those steps would not be relevant in most cases. Digital technology and wireless networks make it possible for a procedure to be updated with current plant status (e.g., work in progress, lock out/tag outs, etc) as well as plant mode on a 
real-time basis. This would make it possible to only present the information (e.g. cautions and warnings) and procedure steps that apply in the current situation to an operator.

\section{CONCLUSIONS}

The purpose of this study was to develop an initial model of procedure usage and derive from that a list of requirements that are necessary for CBPs to improve human performance. The model presented in this paper is a first step in defining how operators interact with procedures, and where errors can occur in that process. The researchers learned that procedural deviations are typically unintentional errors that occur while an operator is attempting to follow the procedure as written. These errors are associated with difficulties in identifying the correct component, understanding the procedure logic and omission of important elements in the process of following a procedure step such as verifying that the expected response was achieved.

The results of this study were based on input from a limited sample of the nuclear industry. Detailed interviews were conducted with operators from a single plant. Insights gained from focus groups that included representatives from a total of four utilities as well as five research institutes also informed the results of this study. The type of information gathered to construct the model of procedure usage (especially with respect to procedure adherence), and ultimately develop the requirements depends largely on the organizational culture that defines the behaviors and attitudes of the field operators studied.

Therefore, before the recommendations presented here are adopted by those wishing to implement CBPs, the results need to be validated to ensure that they are representative of the nuclear industry at large.

The next logical step in this research effort is to validate and extend the findings presented here. The researchers are currently gathering data from another set of utilities to verify the validity of the model of procedure usage and to fill in any gaps. Additionally, the researchers are extending the model to include an in-depth description of the cognitive factors that affect the successful execution of procedures. Both of these efforts will inform a refined list of requirements for CBPs.

While demonstrating opportunities to improve procedure use with CBPs is the main objective of this research, it became apparent during the plant visit that there are many opportunities to improve work processes not directly related to the use of procedures using technology. In a typical day, operators have to gather information from a large number of sources, many of which are maintained on paper or rely on the operator's ability to correctly remember and recall the information when needed. If much of this information could be gathered automatically it could save the operator a lot of time. In order to maximize the human performance improvements that advanced technology can provide, the device that houses the CBP should also have access to all the other forms of information that the operator uses in his day-to-day activities (e.g., work requests, shift turn-over sheets, etc.). Additionally, the CBP system and other workrelated instructions housed on the device should have access to the most up-to date information about plant status, evolutions in progress, and equipments status. This information should be automatically imported into the relevant systems. This may require a great deal of infrastructure improvement for most plants, however, projects that include CBPs systems and other upgrades should consider this.

CBPs provide an opportunity to enhance the safety, efficiency, and accuracy of procedural tasks in the nuclear power industry. If CBPs are to be accepted by operators, utilities, and regulators, they must be designed to take advantage of human capabilities and to mitigate human limitations. An important first step in identifying how CBPs need to be designed to optimally support operators is characterizing what aspects of the current paper-based systems contribute to errors. The model of procedure usage developed in this research effort will help to inform that characterization. Future efforts will refine the model and use the requirements developed from that model to inform the design of a CBP prototype. 


\section{REFERENCES}

Converse, S. (1995). Evaluation of the Computerized Procedure Manual II (COPMA II) (NUREG/CR6398). U.S. Nuclear Regulatory Commission, Washington, DC.

Farris, R. \& Medema, H. (In Press) Integrating Human Performance Into Technology.

Fink, R., Killian, C., Hanes, L., \& Naser, J. (2009). Guidelines for the design and implementation of computerized procedures. Nuclear News. VOL 52 (3), 85-88, 90.

IEEE. (2011). Human Factors Guide for Applications of Computerized Operating Procedure Systems at Nuclear Power Generating Stations and other Nuclear Facilities (P1786). P. 2, New York, NY: Institute of Electrical and Electronics Engineers.

Institute for Nuclear Power. (2009). Procedure Use \& Adherence (INPO 09-004). Rev. 0

O'Hara, J., Higgins, J. C., Stubler, W. F., and Kramer, J. (2000). NUREG/CR-6634 Computer-Based Procedure Systems: Technical Basis and Human Factors Review Guidance, US Nuclear Regulatory Commission, Washington, DC. 
Appendix B

\section{A Model of Operator Interaction with Field Procedures: Insights for Computer-Based Procedures}




\title{
Appendix B
}

\section{A Model of Operator Interaction with Field Procedures: Insights for Computer-Based Procedures}

\author{
Authors \\ Katya Le Blanc \\ Johanna Oxstrand \\ Accepted for publication in the proceeding for the \\ 8th International Conference on Nuclear Plant Instrumentation, Control, and Human-Machine \\ Interface Technologies (ANS NPIC \& HMIT 2012) \\ Proposal submitted \\ March 22, 2012
}

Conference dates

July 22-26, 2012 


\title{
A Model of Operator Interaction with Field Procedures: Insights for Computer-Based Procedures
}

\begin{abstract}
Paper-based procedures (PBPs) are used to manage human performance in the nuclear power industry both in the field, and in the main control room. Though PBPs are viewed as a necessary tool to guide operators through complex tasks, limitations in paper-based systems may increase operator workload and contribute to errors. Plans to upgrade aging plants with digital equipment and wireless technology may present an opportunity to enhance procedures by migrating them to computer-based systems. These computer-based procedures (CBPs) have the potential to enhance human performance by integrating plant status information and automating many tasks (e.g., place-keeping). CBPs have been explored for more than 30 years for use in the main control room; however their actual deployment in the US nuclear plants is yet to be realized. Currently, the Idaho National Laboratory and participants from the nuclear industry are collaborating on a research effort aimed at identifying requirements for CBPs used by field operators. This paper describes the first step in that effort: a qualitative study and the development of a Model of Procedure Usage.
\end{abstract}

\section{INTRODUCTION}

Complex systems and high-risk work environments, such as commercial nuclear power plants, are often heavily dependent on procedures to guide actions taken on the system. Procedures are viewed as a means to maintain a high level of human performance for actions taken by control room operators, field operators, and maintenance technicians. Currently, most nuclear utilities are presenting and maintaining their procedures on paper, i.e. paper-based procedures (PBP). Even though these procedures are an important tool to ensure the safety at the plant, they have been identified as a potential contributor to human errors. This is partly due to the fact that paper-based procedures are static and do not always reflect the current plant conditions. Placekeeping and managing multiple procedures are other factors that may influence the risk of procedure related human errors (Fink, Killian, Hanes, \& Naser, 2009, O’Hara et al., 2000; Converse, 1995). .

The current commercial nuclear power fleet in the U.S. is aging and is therefore undergoing large modernization efforts. As a part of these efforts plants are moving toward digital systems and wireless technology. This trend allows for the transition to computer-based procedures (CBP). A computerbased procedure system (CBPS) is a system where procedures are presented to the operator in an electronic format on a computer display, handheld device, or any other electronic device. Research on CBPs has been conducted since the 1980 s, so the concept is by no means new. However, most of the existing research has focused on emergency operating procedures used in the main control room. More recent work indicates that CBPs might be a viable option to improve human performance for field operators (Farris \& Oxstrand, in press).

CBPs could potentially increase reliability, efficiency, and safety at the plant. A CBPS has the potential to incorporate automatic place-keeping and plant status updates, making the procedures as dynamic as the plant. However, a poorly designed CBPS can have severe negative effect on human performance. Therefore, the design of a CBP should be based on rigorous human factors research
The Idaho National Laboratory is collaborating with participants from the U.S commercial nuclear industry in a research effort which focuses on CBPs for field workers. This includes both field operators and maintenance technicians. The research effort aims to indentify and deploy a common vision of CBPs across the nuclear industry, and to define a path forward to implement CBPS at the utilities.

The first step in this research effort was to collaborate with the utilities to discover what problems they are having with current PBPs which led to the formulation of a problem statement that will guide the overall research effort. Numerous events and subsequent corrective actions are attributed to procedural use and adherence issues in nuclear power plants. The paper-based procedures currently utilized pose challenges in that they are static while actual plant conditions are dynamic. Therefore, the procedures may include sections or steps not applicable to the current situation as well as cautions or warnings that are misleading or confusing given the current plant status. These issues are all known to lead to unintended or erroneous actions.

In order to understand how to best design a CBPS, the current use of PBP systems must be thoroughly understood. This will provide insights into how operators interact with procedure, what potential errors exist, and what cognitive factors are the underlying causes for these potential errors. These insights will be a first step in developing requirements for CBPS for field workers. Currently, there is no detailed description of how operators actually use procedures, nor a systematic description of the cognitive factors that affect successful use of procedures.

Researchers conducted a qualitative study at a nuclear power plant with the objective of developing a model of procedure use that characterizes the procedure following process, the subjective decisions that an operator must make in that process, the techniques he uses to make those decisions, and the underlying cognitive factors that affect the success or failure of those decisions.

\section{METHOD}


The study consists of two parts; 1) a qualitative study conducted at a nuclear power plant, and 2) development of a Model of Procedure Use, which includes the identification of potential errors and cognitive factors.

The first part of the qualitative study was to define the organizational expectations for procedure use and adherence. This was accomplished by reviewing documents on procedure use and adherence from two nuclear power utilities as well as similar documents from the Institute for Nuclear Power Operations (INPO, 2009). The results from the review served as a basis for comparison when evaluating the expected procedure use versus the operator's descriptions of actual procedure use.

The second part of the qualitative study was conducted in four days at a nuclear power plant. The study included the following three data-gathering activities:

1. On-the-job observation of field operators,

2. Structured interviews, and

3. Participation in focus group discussions.

\section{On-the-Job Observation of Field Operators}

The researchers observed a shift turn-over including individual turn-overs and a shift brief. Two field operators were observed while they conducted their initial rounds. One round was conducted in the turbine building and the other was conducted in the service building and outside areas including the cooling towers. During the observations it was captured how the operators were using Personal digital assistants (PDAs) as a tool for their rounds guiding them to components to inspect and values to record.

The following information was captured in the on-the-job observations:

3. A timeline of the tasks the operator executed

4. Answers to the following questions about information flow
a. What information is needed in the field?
b. When is it needed?
c. How is it presented? Is it committed to memory?
d. Who needs it?
e. How is information communicated?
f. What information is needed in parallel?

\section{Semi-Structured Interviews}

Semi-structured interviews were conducted with both field operators and maintenance technicians. Five maintenance technicians and ten field operators were interviewed. The following questions were asked in the interviews:

8. What are the most common reasons for deviating from a procedure?

9. During a typical procedural task, do you have the overall goal of the procedure in mind, or are you focused on executing the current step?

10. When executing a procedural action, do you feel you understand the consequences of that action on the plant?
11. What kind of things would cause you to stop and question whether you can complete a procedure as expected/written?

12. Can you walk me through the process of following a procedure step? What are the subtasks of following a procedure step?

13. On a typical day, how often do you consider stopping the procedure because you are unsure, but ultimately decide not to and go ahead with the procedure? What are your reasons?

14. What kind of information/criteria do you use to decide whether you need to stop and contact a supervisor?

In addition to the predefined questions, researchers asked ad hoc follow-up questions as needed to better understand how operators interact with the current PBPs.

\section{Construction of the Model of Procedure Use}

The data gathered in the qualitative study was used to construct a model of procedure usage that contains the following elements:

1. A detailed task flow illustrating the individual elements in the process of executing a single procedure step. This was constructed using the operator's descriptions of exactly what they do when they are attempting to execute a single procedure step.

2. A description of the techniques used to make decisions outlined in the task flow. This was constructed using the operator's descriptions of exactly how they decide whether they can execute to execute a procedure step as written.

3. A description of the factors that affect the likelihood of errors for each element in the task flow. This was constructed by both: 1) considering operator's descriptions of situations in which they have made errors (or could have made errors), and 2) evaluation of the decision techniques from a psychological and human factors perspective.

4. A description of the cognitive factors that influence the error likelihood for each element. This was constructed by reviewing the current psychological literature for research that is relevant to the errors.

\section{RESULTS}

The researchers used the operators' responses to interview questions, and the information collected in the observations to construct a model of the procedure following process (presented in figure 1). This model is intended to describe the process of following a single procedure step (which would be iterated for each step and sub-step in the procedure) as well as to characterize the operator's interaction with the procedure on a cognitive level. Please note that the model is based solely on information gathered in the qualitative study and may therefore not be a complete characterization of the procedure following process or of the operators' interaction with procedures. 


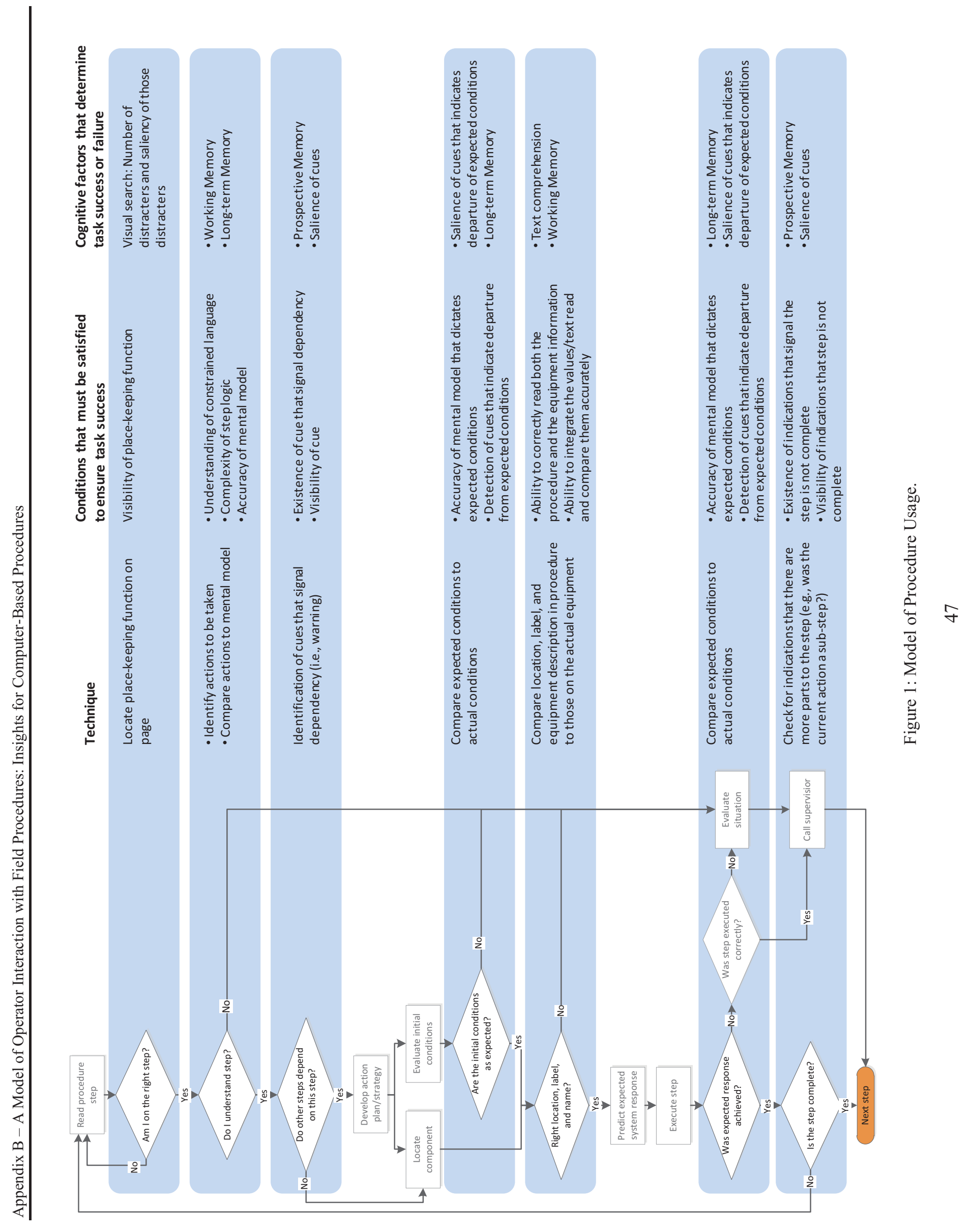




\section{DISCUSSION}

The Model of Procedure Use presented above provides several insights into the potential errors that a field operator could make in executing a procedure when using the current paper-based systems. Additionally, consideration of the cognitive factors presented in the model provides insight into how those errors might be mitigated with a properly designed CBPS. Below is a summary of the important cognitive factors identified in the Model of Procedure Use and a brief discussion of how CBPs can improve human performance for procedure usage.

\section{Memory}

Paper-based systems require the operator to rely a great deal on his memory. Based on the model above, many of the potential errors can be attributed to failures in memory. For example, evaluating the initial conditions and predicting the expected system response require that the operator both remember, and properly integrate, a large amount of information stored in long-term memory. Additionally, tasks such as performing calculations and comparing information in the procedure to equipment in the plant can also heavily tax working memory (Baddeley, 2000). Finally, there are several situations in which an operator needs to remember to do something in the future (e.g., a When/then step where an operator has to do something when a certain condition is met) and he must rely on his prospective memory. In these situations, there is often not a cue present the in the PBP that would signal the operator to complete the action. The fact there are likely intervening tasks and interruptions during the procedure execution may make is more likely that an operator's prospective memory may fail for tat task (Dohdia \& Dismuskes, 2009)

CBPs can be designed to alleviate much of the burden on the operator's memory by automating many of these tasks. A CBPS can make available much of the information that an operator needs to store in long-term memory. With functionality such as the use of barcode scanning for verifying that the operator is working on the correct component, the CBPS can alleviate some of the burden on working memory. Finally, CBPs can provide timely cues that signal an operator to complete a task, rather than relying on his fallible prospective memory.

\section{Visual Search}

Unintentional omission of a step is a common problem with PBPs. In order to find the current step and operator typically has to locate a hand-written place-keeping function on a page of printed text. From a cognitive perspective, the operator must execute a visual search for that place-keeping function. Research shows that the success and timing of visual search varies depending on several factors including the number of distracters and the salience of those distracters. That is, the more distracters (non-place-keeping text) there are on the page and the more salient the distracters are (e.g., bold text in the procedure steps) the more difficult it is to locate the place-keeping function (Itti \& Koch, 2000). Thus, the typical procedure format along with the typical place-keeping method makes it very difficult to locate the current step on the page.

CBPs can automatically track the progress through the procedure and make the current step highly visible by highlighting the current step for the operator, alleviating the burden associate with place-keeping.

\section{CONCLUSIONS}

The model of Procedure Usage Presented in this paper characterizes the field operator's interaction with procedures and provides some initial insights into the underlying cognitive factors that affect success of procedure execution. Additionally the model points to solutions to the potential error in the procedure following process that can be obtained with CBPs.

\section{REFERENCES}

Baddeley, A. D. (2000). The episodic buffer: A new component of working memory? Trends in Cognitive Sciences, 4(11), 417-423. doi: 10.1016/s1364-6613(00)015382

Converse, S. (1995). Evaluation of the Computerized Procedure Manual II (COPMA II) (NUREG/CR-6398). U.S. Nuclear Regulatory Commission, Washington, DC.

Dodhia, R. M., \& Dismukes, R. K. (2009). Interruptions create prospective memory tasks. Applied Cognitive Psychology, 23(1), 73-89. doi: 10.1002/acp.1441

Farris, R. \& Oxstrand, J. (In Press) Integrating Human Performance Into Technology.

Fink, R., Killian, C., Hanes, L., \& Naser, J. (2009). Guidelines for the design and implementation of computerized procedures. Nuclear News. VOL 52 (3), 85-88, 90.

Institute for Nuclear Power. (2009). Procedure Use \& Adherence (INPO 09-004). Rev. 0.

Itti, L., Koch C. (2000). A saliency-based search mechanism for overt and covert shifts of visual attention. Vision Research, 40(10-12), 1489-1506.

O’Hara, J., Higgins, J. C., Stubler, W. F., and Kramer, J. (2000). NUREG/CR-6634 Computer-Based Procedure Systems: Technical Basis and Human Factors Review Guidance, US Nuclear Regulatory Commission, Washington, DC. 


\section{Appendix C}

\section{Requirements for Computer Based-Procedures for Nuclear Power Plant Field Operators - Results from a Qualitative Study}




\title{
Appendix C
}

\section{Requirements for Computer Based-Procedures for Nuclear Power Plant Field Operators - Results from a Qualitative Study}

\author{
Authors \\ Katya Le Blanc \\ Johanna Oxstrand \\ Thomas Waicosky
}

Submitted to

3rd International Conference on NPP Life Management for Long Term Operations (IAEA PLiM 2012)

\begin{abstract}
accepted
December 30, 2011

Full paper submitted

April 30, 2012
\end{abstract}

Conference dates

May 14-18, 2012 


\title{
Requirements for Computer Based-Procedures for Nuclear Power Plant Field Operators Results from a Qualitative Study
}

\author{
Le Blanc, Katya ${ }^{\mathrm{a}}$, J.H. Oxstrand ${ }^{\mathrm{a}}$, T. Waicosky ${ }^{\mathrm{b}}$ \\ ${ }^{a}$ Idaho National Laboratory \\ Battelle Energy Alliance \\ P.O. Box 1625 \\ Idaho Falls, ID 83415-(3605) \\ ${ }^{b}$ Duke Energy \\ Duke Energy Carolinas, LLC \\ CT01A / 4800 Concord Rd. \\ York, SC 29745
}

\begin{abstract}
Although computer-based procedures (CBPs) have been investigated as a way to enhance operator performance on procedural tasks in the nuclear industry for almost thirty years, they are not currently widely deployed at United States utilities. One of the barriers to the wide scale deployment of CBPs is the lack of operational experience with CBPs that could serve as a sound basis for justifying the use of CBPs for nuclear utilities. Utilities are hesitant to adopt CBPs because of concern over potential costs of implementation, and concern over regulatory approval. Regulators require a sound technical basis for the use of any procedure at the utilities; without operating experience to support the use CBPs, it is difficult to establish such a technical basis. In an effort to begin the process of developing a technical basis for CBPs, researchers at Idaho National Laboratory are partnering with industry to explore CBPs with the objective of defining requirements for CBPs and developing an industry-wide vision and path forward for the use of CBPs. This paper describes the results from a qualitative study aimed at defining requirements for CBPs to be used by field operators and maintenance technicians.
\end{abstract}

\section{Introduction}

In complex work environments, such as the nuclear power industry, written procedures are used to guide human operators in a variety of tasks. Currently, most United States nuclear power plants present procedures on paper. Paper based procedures (PBPs) are an important tool for ensuring that operators take the appropriate actions on a system; however many challenges have been identified with PBPs, including:

- Nuclear power plants are dynamic systems, and PBPs have to be written so that they can account for a large variety of possible conditions. Therefore, portions of the procedure may not apply in the current conditions, which could potentially confuse the operator. [1]

- Operators often need to execute more than one procedure at a time, and it can be challenging to manage multiple procedures. [2]

- With PBPs, place-keeping must be done manually, which may increase operator workload and increase the likelihood of errors. [1]

The potential to mitigate some of these challenges by presenting procedures on electronic devices was recognized in the mid 1980's. Several groups designed early computer-based procedure (CBP) systems for example, COMPRO (developed by Westinghouse Electric Corporation), COPMA (developed by The Halden Reactor Project), and the computerized procedures for the French N4 design. CBPs are currently in use or planned to be used in several international nuclear power plants [1]. However, despite the fact that CBPs have been investigated for almost thirty years, they have not yet been deployed in US utilities. One of the reasons for the delay in implementing CBPs may be the fact that there is insufficient information available regarding the effect of CBPs on human performance of procedural tasks. This 
makes it difficult for both utilities and regulators to assess the overall impact that CBPs may have on plant safety and plant performance. A few experimental studies have investigated the effect that CBPs have on operator performance in simulated scenarios [3-8], but the data gathered in these studies does not provide strong evidence that CBP systems will improve operator performance. Thus, it is difficult for utilities to justify the cost of developing, implementing and licensing a CBP system for existing plants.

Despite the lack of operational experience, many utilities are considering CBPs as part of digital upgrades to existing equipment. For existing plants, CBPs may be an important opportunity to increase efficiency by simplifying work processes and the management of procedures. CBPs may also offer an opportunity to enhance human performance and plant safety by providing context-sensitive information and real-time plant status information. However, as with most new technology, it is important to fully understand the impact of the system before implementing it. Most efforts related to CBPs have focused on CBPs for main control room procedures. However, field operators face the same challenges associated with PBPs and may benefit from a switch to CBPs. By proving the potential of CBPs in less risky field operations, it may be possible to justify the next step of adopting CBPs in the main control room, thus forging the path forward for wide-scale CBPs deployment.

Researchers from Idaho National Laboratory, along with participants from the nuclear industry, are working on a research project aimed at identifying a path forward for implementing CBPs, starting with CBPs for field operators. The specific objectives for this project are:

(1) Evaluate utility interest in CBPs.

(2) Determine the challenges utilities are having with current PBP systems.

(3) Identify requirements for CBPs for field procedures to address those challenges.

(4) Develop a prototype CBP system based on the requirements identified.

(5) Define an industry-wide vision and path forward for CBP deployment.

As part of meeting the first three objectives, researchers at INL conducted a qualitative study during plant visits at two utilities. The purpose of the study was to identify how PBPs are used by field operators and develop requirements for CBPs.

\section{Method}

The research conducted in this study consisted of four parts:

(1) A needs assessment to ensure that the research conducted will meet the needs of utilities who wish to implement CBPs

(2) A qualitative study conducted at a nuclear power plant

(3) The development of a model of procedure usage

(4) The development of requirements for CBP systems used by field operators

\subsection{Needs assessment}

The research team conducted the needs assessment in two parts. The first portion of the needs assessment occurred during the first plant visit. The team collected data during focus group discussions. The second portion of the needs assessment included a survey distributed at a meeting during another plant visit.

\subsubsection{Focus Groups}

Researchers conducted several focus group discussions that were aimed at identifying how technology can be used to enhance human performance, and specifically how CBPs might improve performance over PBPs. Four utilities participated in the focus group discussions.

\subsubsection{Survey}


As a follow-up to the focus group discussions, researchers distributed a short survey to identify utilities' current plans for implementing CBPs, current infrastructure in place to support enhanced functionality, such as real-time plant status updates, perceived barriers to implementing CBPs, and the information and support a utility would need in order to overcome those barriers. This survey was distributed to fifteen individuals representing six utilities.

\subsection{Qualitative study}

In order to build a model of procedure usage, researchers conducted a qualitative study at a nuclear power plant. Researchers gathered data for the qualitative study during on-the-job-observations and structured interviews during a plant visit.

\subsubsection{Observations}

Researchers observed two nuclear power plant equipment operators on-the-job. The researchers used a checklist of items to conduct the observations. The following information was captured in the on-the-job observations:

(1) A timeline of the tasks the operator executed

(2) Answers to the following questions about information flow

(a) What information is needed in the field?

(b) When is it needed?

(c) How is it presented? Is it committed to memory?

(d) Who needs it?

(e) How is information communicated?

(f) What information is needed in parallel?

\subsubsection{Interviews}

Researchers conducted semi-structured interviews with both field operators and maintenance technicians. Five maintenance technicians and ten field operators were interviewed. The following questions were asked in the interviews:

(1) What are the most common reasons for deviating from a procedure?

(2) During a typical procedural task, do you have the overall goal of the procedure in mind, or are you focused on executing the current step?

(3) When executing a procedural action, do you feel you understand the consequences of that action on the plant?

(4) What kind of things would cause you to stop and question whether you can complete a procedure as expected/written?

(5) Can you walk me through the process of following a procedure step? What are the subtasks of following a procedure step?

(6) On a typical day, how often do you consider stopping the procedure because you are unsure, but ultimately decide not to and go ahead with the procedure? What are your reasons?

(7) What kind of information/criteria do you use to decide whether you need to stop and contact a supervisor?

In addition to the predefined questions, researchers asked ad hoc follow-up questions as needed to better understand how operators interact with the current PBPs.

\subsection{Development of model}


The data gathered in the qualitative study was used to construct a model of procedure usage that contains the following elements:

(1) A detailed task flow illustrating the individual elements in the process of executing a single procedure step. This was constructed using the operators' descriptions of exactly what they do when they are attempting to execute a single procedure step.

(2) A description of the techniques used to make decisions outlined in the task flow. This was constructed using the operators' descriptions of exactly how they decide whether they can execute a procedure step as written.

(3) A description of the factors that affect the likelihood of errors for each element in the task flow. This was constructed by both: 1) considering operators' descriptions of situations in which they have made errors (or could have made errors), and 2) evaluation of the decision techniques from a psychological and human factors perspective.

(4) A description of the cognitive factors that influence the error likelihood for each element. This was constructed by reviewing the current psychological literature for research that is relevant to the errors.

\subsection{Development of Requirements}

The researchers used the insights gained from the model of procedure usage to develop a set of general requirements for CBPs for field operators. Those requirements were based on an analysis of the model of procedure usage. Researchers considered the factors that affect the likelihood of errors that were identified in the model and evaluated whether they could be mitigated with CBPs. Researchers also reviewed basic psychological and human factors literature to determine if the potential CBP solution may produce unintended consequences (e.g., exacerbating problems by introducing additional interface management tasks). Where there were clear, attainable solutions for the potential errors identified in the model of procedure usage and minimal negative consequences identified, the researchers developed a requirement for CBPs.

In addition to the general set of requirements, the authors also produced a list of specific requirements for CBPs for field operators based on a review of the existing guidance for CBPs. The authors reviewed three documents to produce these requirements: Section 8 of NUREG-0700 [9], the IEEE standard 1786 [10] and an in press NUREG/CR [11]. The requirements were selected and adapted from the list of human performance issues identified in [11] Researchers selected only the issues that were relevant to field operating procedures based on the assumption that field operating procedures are unlikely to have procedure-based automation, as most of the equipment is operated locally (thus issues with procedurebased automation were excluded from the requirements). Similarly, it is unlikely that field CBPs will include soft controls, so issues related to the use of soft controls were also excluded.

\section{Results}

\subsection{Needs Assessment}

The results from the focus group discussions and the survey were analyzed separately.

\subsubsection{Focus Groups}

The focus group discussions revealed the following insights:

- Utilities need a set of requirements and standards for CBPs in order to implement a CBP project

- CBPs must be designed to enhance human performance compared to PBPs; a CBP system that simply mimics PBPs and displays them on an electronic device would not be enough of an improvement to justify a migration to CBPs 
- Due to regulatory requirements, utilities do not wish to take the risk of implementing CBPs alone; they would prefer to move together with CBPs as a whole industry

\subsubsection{Survey}

The researchers calculated the proportion of "yes" responses to forced-choice yes/no survey questions. $100 \%$ of the utilities surveyed reported that CBPs for field operators were part of their long-term vision. $66 \%$ reported that CBPs for control room operators were in the long-term vision.

The researchers coded responses to open ended survey questions according to a list of categories developed after the data was collected. The categories that were developed for these questions are presented below in table 1 along with the proportion of responses that fit into that category.

Table I. Proportion of responses to needs assessment survey questions organized by category.

\begin{tabular}{|c|c|}
\hline Question & Categories and Proportion of Responses \\
\hline What are your reasons for considering CBPs? & $\begin{array}{l}\text { Configuration and control of procedures }-30 \% \\
\text { Context sensitivity of procedures }-20 \% \\
\text { Procedure tracking }-20 \% \\
\text { Human performance improvement }-20 \%\end{array}$ \\
\hline $\begin{array}{l}\text { What functionality would you like to see in } \\
\text { CBPs }\end{array}$ & $\begin{array}{l}\text { Context Sensitivity }-55 \% \\
\text { Specific interface issues }-28 \% \\
\text { Ability to update plant status based on procedural } \\
\text { actions }-17 \%\end{array}$ \\
\hline $\begin{array}{l}\text { What would your utility/plant need in order to } \\
\text { move forward with a CBP project? }\end{array}$ & $\begin{array}{l}\text { Successful implementation at another utility }-25 \% \\
\text { Infrastructure improvements }-25 \% \\
\text { Proof of concept }-16 \% \\
\text { Requirements and standards across industry }-16 \% \\
\text { Other }-18 \%\end{array}$ \\
\hline
\end{tabular}

\subsection{Model of Procedure Usage}

The researchers developed a model of procedure usage based on the observations and interviews. A detailed description of the development of the model and a detailed presentation of the model can be found in [12]. The model of procedure usage was used to develop an initial list of requirements for CBPs presented in the next section.

\subsection{Requirements}

In order to address the specific challenges identified in the qualitative study, CBPs need to meet the following general requirements. It is important to note that this is not a complete set of requirements for CBPs. These requirements are based on the specific issues that were identified in the qualitative study. The requirements presented here should be viewed as a minimum set of requirements for CBPs intended 
to address some of the challenges that field operators have identified associated with their current use of paper-based procedures.

(1) CBPs should guide operators through the logical sequence of the procedure. The CBPs should be designed so that they automatically take the operators through the specified procedure path based on initial conditions and operator input.

(2) CBPs should ease the burden of place-keeping for the operator. CBPs should keep track of where the operator is in the procedure, should mark steps as completed, and should highlight the current step.

(3) CBPs should make the action steps more distinguishable from information gathering steps. CBPs should use some method to differentiate steps for which an operator must actually manipulate the plant versus when he must simply check a condition or value.

(4) CBPs should alert the operator to dependencies in steps more visibly. Typically, the operator has to rely on previous experience or on a caution or warning in order to identify the situations in which he needs to read ahead in the steps. CBPs should alert the operator when he reaches a step with dependencies, rather than relying on him to read ahead (or remember from previous experience) to detect the dependency. Additionally, if a CBP system has access to real-time plant data the system should alert the operator when plant status changes in a manner that affects the operator's task.

(5) CBPs should ease the burden of correct component verification (CCV) for the operator. CBPs should employ some method to automate CCV (e.g., include barcode scanning or text recognition functionality).

(6) CBPs should ease the identification and support assessment of the expected initial conditions. Some method of illustrating the expected initial conditions in a simple and easy to understand manner should be available to the operator through the CBPs. For example a schematic or piping and instrument diagram of the relevant equipment could be available on-demand.

(7) CBPs should ease the identification and support assessment of the expected plant and equipment response. Some method of illustrating the expected equipment and plant response in a simple and easy to understand manner should be available to the operator through the CBPs. For example a schematic or piping and instrument diagram of the relevant equipment could be available on-demand.

(8) CBPs should include functionality that improves communication. In the event that an operator encounters a situation that he needs to contact a supervisor to resolve, he needs to be able to efficiently and accurately describe the problem. Tools such as texting, capturing photographs and streaming video have all been identified as highly desirable to have built into any device that display CBPs.

Additionally, CBPs must also be designed so that they are consistent with existing guidance and human factors engineering principles. Thus CBPs for field operators must also meet the following specific requirements identified by the review of guidance documents:

- CBPs should be designed so that the operator controls the procedure pace.

- CBPs should make calculations when the necessary information is available.

- The CBP system should alert users when procedure steps or conditions have been violated.

- The CBP system should alert users when conditions require transitioning to another procedure.

- When the necessary information is available to the CBP, the procedure system should evaluate step logic.

- The CBP system should be designed so that it is easy for the user to "undo" an unintended or incorrect action (an error of commission). 
- The CBP should provide dynamic, context-sensitive information.

- The CBP system should automatically monitor users.

- The CBP system should allow the operator to look ahead and back in the procedure.

- The CBP system should provide seamless navigational transitions to other active procedure(s), to branches and transitions in the same procedures, and to supplemental information required by the procedure.

- The CBP system should indicate when there are multiple active procedures.

- The CBP system should provide flexibility in the amount of information/level of detail where appropriate.

- The CBPs should provide identification of active procedure information (title, revision number, etc.).

- The CBP should provide high-level information related to procedure goals.

- The CBP system should provide identification of procedure system status.

- The CBP should provide indication of user input requirements.

— The CBP system should provide user support (e.g., a help function).

\section{Conclusions}

CBPs have been identified as a way to contribute to efficiency and safety of the current US nuclear fleet by reducing human error. However, most existing nuclear power plants in the US are still using PBPs to guide procedural activities. The researchers have established that there is substantial interest in the US nuclear power industry to migrate to CBPs in the near future. In order for deployment of CBPs in the existing nuclear fleet to occur, the industry needs a set of standards or requirements for CBPs and an example of success. The researchers have taken the first step in developing a set of requirements and standards for field procedures by identifying the how operators use PBPs, and how they may contribute to errors. The researchers have also identified a preliminary set of requirements that CBPs must employ in order to mitigate those potential errors. The researchers also reviewed the existing guidance on CBPS and selected requirements for field CBPs based on that guidance. Together, these requirements will serve as a starting point to develop an initial CBPs prototype for field procedures. The next step in this research effort is to design a CBP prototype based on these initial requirements, evaluate that prototype in a realistic setting, and update the requirements based on the findings. 


\section{REFERENCES}

[1] FINK, R., et al., Guidelines for the design and implementation of computerized procedures. Nuclear News, VOL 52 (3), 85-88 (2009).

[2] CONVERSE, S. Evaluation of the Computerized Procedure Manual II (COPMA II) (NUREG/CR-6398), U.S. Nuclear Regulatory Commission, Washington (1995).

[3] HUANG, F.-H., HWANG, S-L., Experimental studies of computerized procedures and team size in nuclear power plant operations, Nuclear Engineering and Design, 239, 373-380 (2009).

[4] JEFFROY, F., \& CHARRON, S., From safety assessment to research in the domain of human factors: The case of operations with computerised procedures. Paper presented at IEEE 6th annual Human Factors Meeting, Orlando FL (1997).

[5] LEE, Y., et al., Reducing cognitive workload of a computer based procedure system. International Journal of Human-Computer Studies 63, p587-606. (2004)

[7] XU, S., et al., An ergonomics study of computerized emergency operating procedures: presentation style, task complexity, and training level, Reliability Engineering and System Safety 93 (10), 1500-1511. (2008).

[8] ROTH, E. \& O'HARA, J, Integrating digital and conventional human system interface technology: Lessons learned from a control room modernization program (NUREG/CR-6749), Washington, D.C.: U.S. Nuclear Regulatory Commission (2002).

[9] O'HARA, J., et al., Computer-Based Procedure Systems: Technical Basis and Human Factors Review Guidance, NUREG/CR-6634, Washington, DC: U.S. Nuclear Regulatory Commission (2000).

[10] IEEE, Guide for Human Factors Applications of Computerized Operating Procedure Systems (COPS) at Nuclear Power Generating Stations and Other Nuclear Facilities, IEEE Std 17862011. 1-38 (2011).

[11] Le BLANC, K., et al., Human Factors Guidance for the Assessment of Computerized Procedures. (NUREG/CR), Washington, D.C.: U.S. Nuclear Regulatory Commission (In Press).

[12] LE BLANC, K. OXSTRAND, J, A Model of Operator Interaction with Field Procedures: Insights for Computer-Based Procedures, Manuscript submitted for publication. 
Appendix D

\section{Literature Reviewed}




\section{Appendix D}

\section{Literature Reviewed}

During the literature review process the research team reviewed the documents listed in this appendix. The literature is grouped into six groups. The groups are explained in the table below.

\begin{tabular}{|l|l|}
\hline \multicolumn{1}{|c|}{ Group } & \multicolumn{1}{c|}{ Description } \\
\hline INL Documents & Research papers reflecting research efforts conducted by INL \\
\hline Research Documents & $\begin{array}{l}\text { Research papers and reports produced by national and } \\
\text { international organizations }\end{array}$ \\
\hline Halden Documents & $\begin{array}{l}\text { Research reports reflecting research efforts conducted by the } \\
\text { Halden Reactor Project }\end{array}$ \\
\hline NRC Documents & Documents published by NRC \\
\hline IEEE Documents & Documents published by IEEE \\
\hline EPRI Documents & Documents published by EPRI \\
\hline INPO Documents & Documents published by INPO \\
\hline Procedure Professionals Association & Documents published by Procedure Professionals Association \\
\hline Industry Documents & Nuclear power utilities' internal documents \\
\hline
\end{tabular}

\section{Documents from Idaho National Laboratory (INL)}

Boring, R. L., Gertman, D. I., and Le Blanc, K. (2011). Human Reliability Analysis for Computerized Procedures. Proceedings of the Human Factors and Ergonomics Society Annual Meeting, September 2011 55: 1720-1724.

Gertman, D.I., Le Blanc, K., \& Boring, R.L. (2011). Review of Computerized Procedure Guidelines for Nuclear Power Plant Control Rooms. Proceedings of the Human Factors and Ergonomics Society Annual Meeting, September 2011 55: 1476-1480.

\section{Research Documents}

Byrd, K. S., and Caldwell, B. S. (2011). Increased Memory Load During Task Completion When Procedures are Presented on Mobile Screens. Behaviour \& Information Technology, 30:5, 643-658.

Caldwell, B. S. (2008). Information Alignment and Knowledge Synchronization in Spaceflight Operations. SAE Technical Paper 2008-01-2102, 2008, doi:10.4271/2008-01-2102.

Byrd, K. S., and Caldwell, B. S. (2009). From UMPCs to Cell Phones: How Does Diminishing Screen Real Estate Affect Screen Access and Working Memory? Proceedings of the Human Factors and Ergonomics Society Annual Meeting, October 2009, 53: 960-964.

Huang, F-H., and Hwang, S-L. (2009). Experimental Studies of Computerized Procedures and Team Size in Nuclear Power Plant Operations. Nuclear Engineering and Design, 239,373-380.

Hong, J-H., Lee, M-S., and Hwang, D-H. (2009). Computerized Procedure System for the APR1400 Simulator. Nuclear Engineering and Design, 12, 3092-3104. 
Dekker, S. (2006). The Field Guide to Understanding Human Error. Ashgate Publishing Company.

Fink, R. T., Killian, C.D, and Naser, J. A. (2009). Guidelines for the Design and Implementation of Computerized Procedures. Nuclear News, I\&C and Human Factors Special Section, March 2009.

O’Hara, J. M., Pirus, D., and Beltratcchi, L. (2004). Information Display: Considerations for Designing Computer-Based Display Systems. Proceedings of the $4^{\text {th }}$ International Topical Meeting on Nuclear Plant Instrumentation Control and Human Machine Interface Technologies, Columbus, Ohio, September 19-22, 2004.

Park, J. \& Jung, W. (2007). A study on the development of a task complexity measure for emergency operating procedures of nuclear power plants. Reliability Engineering \& System Safety.92 (8), pp. $1102-1116$.

Kortenkamp, D., Bonasso, R. P., Schreckenghost, D. (2006). Procedures as a Gateway to Spacecraft Autonomy. Proceedings of the AAAI Fall Symposium on Spacecraft Autonomy 2006.

Hwang, F-H, and Hwang, S-L. (2003): Design and Evaluation of Computerized Operating Procedures in Nuclear Power Plants. Ergonomics, 46:1-3, 271-284.

Jung, Y., Shin, Y., and Park, I. (2000). An Incremental Objective Achievement Model in Computerized Procedure Execution. Reliability Engineering \& System Safety. 70, 185-195.

Theureau, J., Jeffroy, F., and Vermersch, P. (2000). Controling a Nuclear Reactor in Accidental Situations with Symptom-based Computerized Procedures: a Semiological \& Phenomenological Analysis. Proceedings of the CSEPC 2000, Taejon, Corée, November 22-25 2000.

Novick, D. G. (2000). A Why-What-How Tool for Development and Documentation of Operating Procedures. Proceedings of the IEEE professional communication society international professional communication conference and Proceedings of the 18th annual ACM international conference on Computer documentation: technology \& teamwork, 55-68.

Theureau, J. (1998). Use of Nuclear Control Room Simulators for Research and Development. Proceedings of the 7th IFAC/IFIP/IFORS/IEA Symposium on Analysis, design and evaluation of man-machine systems, Kyoto, September 16-18, 1998.

Jeffron, F., and Charron, S. (1997). From Safety Assessment to Research in the Domain of Human Factors: The Case of Operation with Computerized Procedures. Proceedings of the IEEE $6^{\text {th }}$ annual Human Factors Meeting, 13/5 - 1310.

Xu, S., Song, F., Li, Z.Z., Zhao, Q. Y., Luo, W., He, X.H., and Salvendy, G. (2008). An Ergonomics Study of Computerized Emergency Operating Procedures: Presentation Style, Task Complexity, and Training Level, Reliability Engineering and System Safety, 93 (10), 1500-1511.

Lee, Y., Hwang, S., and Wang, E. (2004). Reducing Cognitive Workload of a Computer Based Procedure System. International Journal of Human-Computer Studies 63, 587-606.

Chung, Y. H., Daihwan Min; Kim, B. R. (2002). Observations on Emergency Operations using Computerized Procedure System. Proceedings of the 2002 IEEE $7^{\text {th }}$ Conference on Human Factors and Power Plants, 4-61- 4-65.

\section{Documents from The Halden Reactor Project}

Andresen, G., Svengren, H., Heimdal, J. O., Nilsen, S., Hulsund, J-E., Bisio, R., and Debroise, X. (2004). Procedure Automation: the Effect of Automated Procedure Execution on Situation awareness and Human Performance. HWR - 759. Institutt for Energiteknikk, OECD Halden Reactor Project, Halden Norway. 
O'Hara, J.; Pirus, D.; Nilsen, S.; Bisio, R.; Hulsund, J.-E.; Zhang, W. (2003). Computerisation of Procedures. Lessons Learned and Future Perspectives. HWR - 355. Institutt for Energiteknikk, OECD Halden Reactor Project, Halden Norway.

Andresen, G., Pirus, D., and Svengren, H. (2002). Procedure Automation and Human Performance: An Explorative Study Using the Fitness Simulator. HWR - 707. Institutt for Energiteknikk, OECD Halden Reactor Project, Halden Norway.

Forzano, P., Fantoni,P.F., Ruiperez. J.A.M. (1999). Feasibility Study Of A Structural Approach In Procedure Automation: An Application To Severe Accident Management Guidelines In Cofrentes NPP. HWR - 583. Institutt for Energiteknikk, OECD Halden Reactor Project, Halden Norway.

Zhang, W. (1999). Verification of Operator Procedures by Model Checking. HWR - 582. Institutt for Energiteknikk, OECD Halden Reactor Project, Halden Norway.

Bjorlo, T., Harmon, D., Lirwall, P., Ness, E., Nilsen, E., Sivertsen, T., Tiegen, J.,and De Vlaminck, M. (1996). The Halden Reactor Project Workshop Meeting on Computerised Procedures. HWR - 439 Institutt for Energiteknikk, OECD Halden Reactor Project, Halden Norway.

Ylikoski, K., and Dahll, G. (1992). Verification of Procedures. HWR - 318. Institutt for energiteknikk, OECD Halden Reactor Project, Halden Norway.

Teigen, J., Nilsen, S., and Owre, F. (1991). Operator Advisory Systems and Procedure Synthesis - A Literature Survey of Some Systems and Methods. HWR - 285. Institutt for Energiteknikk, OECD Halden Reactor Project, Halden Norway.

Larsen, J.S., Lund, E.J., Nilsen, S.R., \& Owre, F. (1987). Computer Aided Procedure Execution. HWR 209. Institutt for Energiteknikk, OECD Halden Reactor Project, Halden Norway.

Owre, F. (1986). Functional Requirements to a System for Computer Aided Procedure Execution. HWR 156. Institutt for Energiteknikk, OECD Halden Reactor Project, Halden Norway.

Larsen. J. S. (1986). PROLA, A Language Specifically Designed for use in Computerized Procedure Applications. HWR - 180. Institutt for Energiteknikk, OECD Halden Reactor Project, Halden Norway.

Dahll, G., Haugset, K., Nilsen, S.R., and Owre, F. (1985). Proposal for the Development of a Computerized Procedure System. HWR - 143. Institutt for Energiteknikk, OECD Halden Reactor Project, Halden Norway.

Hollnagel, E., and Owre, F. (1984). The NORS/HALO System: Background and Methodology of Experiment 1. HWR - 090. Institutt for Energiteknikk, OECD Halden Reactor Project, Halden Norway.

Halden Reactor Project. (1984). Report on the Workshop Meeting on Computerisation of Procedures and Information Presentation Principles. HWR - 110. Institutt for Energiteknikk, OECD Halden Reactor Project, Halden Norway.

Halden Reactor Project. (1981). Report of the Workshop Meeting on Computer-Based Operation Procedures and Maintenance Status Information. HWR - 038. Institutt for Energiteknikk, OECD Halden Reactor Project, Halden Norway.

\section{Documents from The Nuclear Regulatory Commission (NRC)}

O’Hara, J. M., Brown, W. S., Lewis, P. M., and Persensky, J. J. (2002). Human-System Interface Design Guidelines, NUREG-0700, Rev. 2.Washington, DC: US Nuclear Regulatory Commission. 
O’Hara, J. M., Higgins, J. C., Persensky, J. J., Lewis, P. M., and Bongarra, J. P. (2004). Human Factors Engineering Program Review Model, NUREG-0711, Rev. 2. Washington, DC: U.S. Nuclear Regulatory Commission.

O’Hara, J. M., Higgins, J. C., Stubler, W. F., and Kramer, J. (2000). Computer-Based Procedure Systems: Technical Basis and Human Factors Review Guidance, NUREG/CR-6634. Washington, DC: U.S. Nuclear Regulatory Commission.

U.S. Nuclear Regulatory Commission. (2007). Digital Instrumentation and Controls DI\&C-ISG-05, Task Working Group \#5: Highly-Integrated Control Room - Human Factors Issues (HICR - HF), Interim Staff Guidance, Rev 0. Washington, DC: U.S. Nuclear Regulatory Commission.

Converse, S. A. (1995). Evaluation of the Computerized Procedures Manual II (COPMA II), NUREG/CR-6398. Washington, DC: U.S. Nuclear Regulatory Commission.

Roth, E. and O’Hara, J. (2002). Integrating Digital and Conventional Human System Interface Technology: Lessons Learned from a Control Room Modernization Program , NUREG/CR-6749. Washington, D.C.: U.S. Nuclear Regulatory Commission.

\section{Document from the Institute of Electrical and Electronics Engineers (IEEE)}

"IEEE Guide for Human Factors Applications of Computerized Operating Procedure Systems (COPS) at Nuclear Power Generating Stations and Other Nuclear Facilities," IEEE Std 1786-2011, vol., no., pp.1-38, Sept. 22 2011, doi: 10.1109/IEEESTD.2011.6029264.

\section{Documents from the Electric Power Research Institute (EPRI)}

EPRI 1015313. (2007). Computerized Procedures - Design and Implementation Guidance for Procedures, Associated Automation, and Soft Controls, Draft Report.

EPRI 1011851. (2005). Development of Guidance for the Proper Design and Use of Automation in Nuclear Power Plants.

\section{Document from the Institute of Nuclear Power Operations (INPO)}

INPO 09-004. (2009). Procedure Use \& Adherence, Rev. 0, INPO Good Practice.

\section{Procedure Professionals Association Documents (PPA)}

Procedure Professionals Association. (2011). Procedure Process Description, PPA AP-907-001, Rev. 1. Procedure Professionals Association. (2011). Procedure Writers' Manual, PPA AP-907-005, Rev.1.

\section{Nuclear Utility Documents}

Duke Energy Corporation. (2011). Administrative Instructions for Technical Procedures, Nuclear System Directive, NSD 703, Rev. 31, 11/01/2011.

Duke Energy Corporation (2011). Technical Procedure Use and Adherence, Nuclear System Directive, NSD 704, Rev. 19, 06/09/2011. 
Duke Energy Corporation (2011). Human Performance Program, Nuclear System Directive, NSD 129, Rev. 2, 12/13/2012.

Duke Energy Corporation (2011), Procedure Writing Guide, Operations Management Procedure (OSG), Rev. 23, 09/02/2011. 


\section{Appendix E}

\section{The Protocol Used In The Qualitative Study}




\section{Appendix E}

\section{The Protocol Used in the Qualitative Study \\ Goals of the Qualitative Study}

- Validate/refine the current problem statement

- Develop a model of procedure usage

- Develop an information flow diagram

- Determine the feasibility of some of the potential solutions

- Determine requirements.

\section{Introduction to the Operators}

The purpose of our research is to discover ways to improve your work environment by making your job safer, easier, and more efficient through the use of computer-based procedures. For us to get the most out of these interviews, we need honest and candid answers to these questions. Remember that all of the information we collect will be anonymous. The answers you provide will not be traceable to you as an individual and individual responses will not be shared with anyone.

\section{Validate/Refine the Current Problem Statement}

\section{Hypotheses}

Procedural non-adherence and decision-making by plant personnel can be greatly improved through maximization of situational awareness with the development of procedures that are both dynamic and context sensitive.

\section{Problem Statement}

Numerous events and subsequent corrective actions are attributed to procedural usage and adherence issues in nuclear power plants (NPPs). The Paper-Based Procedures (PBPs) currently utilized pose challenges in that they are static while actual plant conditions are dynamic. Therefore, the procedures may include sections or steps not applicable to the current situation as well as cautions or warnings that are misleading or confusing given the current plant status. These issues are all known to lead to unintended or erroneous actions.

\section{Vision Statement}

Operator performance and ultimately, plant performance may be greatly improved by significant improvements in how procedure usage and adherence is addressed with technology. Plans to upgrade existing plants with digital equipment and wireless technology present an opportunity to enhance procedures by transforming the existing PBPs to Computer-Based Procedures (CBPs). These CBPs have the potential to integrate plant information including plant mode, equipment status, and procedure relevant plant parameters to make it readily available to plant personnel in real time. CBPs with this enhanced functionality will be dynamic and context-sensitive, affording the opportunity to mitigate many of the issues associated with static PBPs. 


\section{Develop a Model of Procedure Usage}

Develop a task flow diagram or a timeline of tasks based on the observations (starting with a pre-job brief and ending with a post-job brief is it exists)

\section{Determine how procedures are used in the field}

1. What are the subtasks in completing a procedure step?

2. What kind of things would cause you to stop and question whether you can complete a procedure as expected/written?

- Determine decision points in the procedure

- What decisions are dictated by operator judgment?

- What decisions are dictated by procedures?

- What decisions are dictated by work processes?

3. On a typical day how often do you encounter situations that require you to stop and evaluate whether you need to contact a supervisor?

4. On a typical day, how often do you consider stopping the procedure because you are unsure, but ultimately decide not to and go ahead with the procedure? What were your reasons?

5. What kinds of information/criteria do you use to decide whether you need to stop and contact a supervisor?

6. On a typical day, do you feel you have enough time to complete the tasks required of you? Why/Why not?

7. Do you feel you have the necessary knowledge to make independent decisions while out in the field? Why/why not?

8. What are the most common reasons for deviating from a procedure?

9. During a typical task, while working on a procedure, do you have the overall goal of the procedure in mind, or are you focused on executing the current step?

10. When executing a procedural action, do you feel you understand the consequences of that action on the plant?

11. What features would be necessary for CBPs to improve your work processes?

12. What features would be nice?

13. What are some things do you NOT want to see in CBPs?

\section{Develop an Information Flow Diagram}

We need to determine what information -in addition to procedures - equipment operators need to complete procedural tasks. According to some of the information and insights that the Human Performance Project discovered, any technology deployed for field operators would ideally be in the form of one device with a single interface. Thus, CPs in the field should be developed within the context of the other needs. We need to answer the following questions.

- What information is needed in the field?

- When is it needed?

- How is it presented? Is it committed to memory?

- Who needs it? 
- How is information communicated?

- What information that is not currently available would be useful to have?

- What information is needed in parallel?

- What tools/devices do the operators use?

\section{Determine the Feasibility of Some of the Potential Solutions}

- How can we provide the operators with real time (or near time) information about plant status?

- Barcode scanning?

- Wireless networks?

- Other technologies?

- How can we provide near time status without barcodes and wireless?

- What steps/tasks that can be done automatically with CBPs?

- Verify current procedure against hard copy. Current version of procedure will be downloaded automatically

- Preparation for Procedure Use: IC and prerequisites can be checked automatically

- Etc. (there are several appendices in NSD 704 that have instructions for activities (mostly information gathering) that I believe could be easily automated without much risk...we need to verify the feasibility of this).

\section{Determine Requirements}

\section{CBPs}

- Procedures must be updated based on plant status

- Plant Mode

- Plant Configuration

- Real-time or Near-time

- PDFs on a Portable Device would not be an improvement over paper-based systems

- Usable HSI

- Flexible and efficient navigation

- Seamless transition to other applications (i.e., any forms or other programs that are on the device)

- Communication tools (e.g., ability to text supervisor)

- $\quad$ BPs must be presented on a single device that encompasses all of the tools that an operator needs in the field.

- $\quad$ CBP system needs to support a global view of the procedures and their effect on the plant

Device

- Barcode Scanner

- Wireless Capability

- Camera (still and video)

- Field rugged. 


\section{Appendix F}

\section{Utility Survey}




\section{Appendix F}

\section{Utility Survey}

The following questions were asked in the utility survey conducted during the LWRS utility working group meeting in March 2012.

1. Utility/plant you are representing:

2. Your general role at the plant (e.g., operator, manager, trainer, etc.):

3. Are CBPs currently in your plant/utilities long term vision? Please answer yes or no to the following.

- Control Room CBPs?

- Field CBPs?

4. If so, what are your reasons for considering CBPs?

5. What infrastructure does your plant currently have in place? Please circle all that apply.

Equipment barcodes

Wireless Network

Electronic Devices used by field operators (e.g., PDAs for rounds)

Other

6. For any of the infrastructure you do not have in place, is your plant planning to install/ implement in the near future? Please briefly describe your plans.

7. What functionality would you like to see in CBPs?

8. What are the barriers you see to implementing CBPs (is any)? Please circle all that apply.

Infrastructure

Regulatory approval

Cost

Availability of suitable systems

Other (please describe briefly)

9. What would your utility/plant need in order to move forward with a CBP project?

10. Have you reviewed any potential CBP solutions?

If so, what systems?

What were/are your reasons for rejecting or accepting a system/solution? 